Portland State University

PDXScholar

Spring 1-1-2012

\title{
Community Earth System Model: Implementation, Validation, and Applications
}

William Christian Porter

Portland State University

Follow this and additional works at: https://pdxscholar.library.pdx.edu/open_access_etds

Part of the Atmospheric Sciences Commons, and the Climate Commons Let us know how access to this document benefits you.

\section{Recommended Citation}

Porter, William Christian, "Community Earth System Model: Implementation, Validation, and Applications" (2012). Dissertations and Theses. Paper 547.

https://doi.org/10.15760/etd.547

This Thesis is brought to you for free and open access. It has been accepted for inclusion in Dissertations and Theses by an authorized administrator of PDXScholar. Please contact us if we can make this document more accessible: pdxscholar@pdx.edu. 


\title{
Community Earth System Model:
}

Implementation, Validation, and Applications

\author{
by
}

\section{William Christian Porter}

A thesis submitted in partial fulfillment of the requirements for the degree of

\author{
Master of Science \\ in \\ Physics
}

Thesis Committee:

Aslam Khalil, Chair

Kelley Barsanti

Andrew Rice

Chris Butenhoff

Portland State University

(C) 2012 


\begin{abstract}
The Community Earth System Model (CESM) is a coupling of five different models which are combined to simulate the dynamic interactions between and within the Earth's atmosphere, ocean, land, land-ice, and sea-ice. In this work, the installation and testing of CESM on Portland State University's Cluster for Climate Change and Aerosol Research (CsAR) is described and documented, and two research applications of the model are performed. First, the improved treatment of cloud microphysics within recent versions of CESM's atmospheric module is applied to an examination of changes in shortwave cloud forcing (SWCF) and results are compared to output from older versions of the model. Second, the CESM model is applied to an examination of the effect that increased methane $\left(\mathrm{CH}_{4}\right)$ concentrations have had on the catalytic destruction of ozone $\left(\mathrm{O}_{3}\right)$ by ozone depleting compounds (ODCs) such as chlorofluorocarbons (CFCs) and nitrous oxide $\left(\mathrm{N}_{2} \mathrm{O}\right)$.
\end{abstract}




\section{Acknowledgements}

I would like to thank Dr. Aslam Khalil, Dr. Kelley Barsanti, and the rest of my thesis committee for their guidance and support during the course of this work. I would also like to express my thanks to the rest of the Khalil research group for their feedback, input, and patience. Finally, love and gratitude to my beautiful wife and son; you are the means and the end. 


\section{Contents}

Abstract

Acknowledgements $\quad$ ii

List of Tables $\quad$ v

List of Figures $\quad$ vi

Chapter 1: Community Earth Systems Model on CsAR 1

1.1 Global Climate Models . . . . . . . . . . . . . . . . . . . 1

1.2 CAM: The Community Atmosphere Model . . . . . . . . . . . . . . . 4

1.3 Cluster for Climate Change and Aerosol Research . . . . . . . . . . . 4

1.4 Installation of CESM . . . . . . . . . . . . . . . . . 5

$\begin{array}{ll}\text { Chapter 2: CESM Validation and Testing } & 7\end{array}$

2.1 Model Functionality and Load Balancing . . . . . . . . . . . . 7

2.2 Error Growth Test . . . . . . . . . . . . . . . . . . 7

2.3 30-Year Validation Run . . . . . . . . . . . . . . . . . . 9

Chapter 3: Indirect Effect of Aerosols $\quad 11$ 
3.1 Aerosols in CAM5 . . . . . . . . . . . . . . . . . . . . . 11

3.2 Short Wave Cloud Forcing Comparison . . . . . . . . . . . . . . 13

$\begin{array}{lr}\text { Chapter 4: The Impact of Methane on Ozone Loss } & 18\end{array}$

4.1 Chemistry Background . . . . . . . . . . . . . . . . 18

4.2 WACCM Cases . . . . . . . . . . . . . . . . . . 21

Chapter 5: Conclusions $\quad 32$

5.1 CESM Ported Successfully to PSU Research Cluster . . . . . . . . . 32

5.2 Buffering Effect of Increased Methane on Stratospheric Ozone $\ldots . .32$

$\begin{array}{ll}\text { Bibliography } & 34\end{array}$

$\begin{array}{ll}\text { Appendix A: CESM Dependencies } & 37\end{array}$

Appendix B: CESM Porting and Operation $\quad 39$ 


\section{List of Tables}

4.1 WACCM Run Descriptions . . . . . . . . . . . . . . . . . . . 21 


\section{List of Figures}

1.1 Land and ocean distribution for Manabe's 1969 coupled climate model. 2

1.2 Latitudinal distributions of zonal mean temperature at $500 \mathrm{mb}$ and 1,000 mb levels for Manabe's 1969 model. . . . . . . . . . . . . . . . . 3

1.3 The coupled modules of CESM $\ldots \ldots \ldots \ldots$

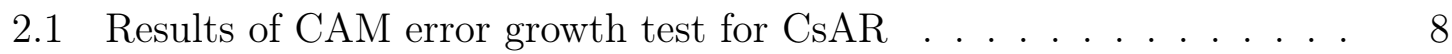

2.2 Comparison of averaged latitudinal precipitation rates, surface pressures, and surface temperatures $\ldots \ldots \ldots \ldots \ldots$

2.3 Average temperature profile comparison . . . . . . . . . . . . . 10

3.1 Preindustrial SWCF in CAM4 and CAM5 . . . . . . . . . 15

3.2 Change in SWCF using CAM4 and CAM5 . . . . . . . . . 16

3.3 Change in SWCF vs. change in AOD using CAM4 and CAM5 . . . 17

4.1 Average $\mathrm{O}_{3}$ column for 4 primary cases $\ldots \ldots \ldots \ldots \ldots$

4.2 Change in $\mathrm{O}_{3}$ density vertical profile with addition of $\mathrm{CFCs} \ldots 26$

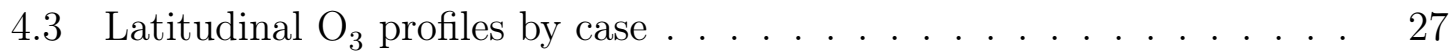

4.4 Impact of $\mathrm{CFCs}$ on $\mathrm{O}_{3}$ column $\ldots \ldots \ldots \ldots \ldots \ldots \ldots$

4.5 Impact of $\mathrm{CH}_{4}$ on $\mathrm{O}_{3}$ column $\ldots \ldots \ldots \ldots \ldots \ldots$

4.6 Amount of $\mathrm{O}_{3}$ "protected" from $\mathrm{CFCs}$ by increase to modern $\mathrm{CH}_{4}$. . 30 
4.7 Latitudinal averages of $\mathrm{O}_{3}$ column at fine and coarse model resolutions. 31 


\section{Chapter 1: Community Earth Systems Model on CsAR}

\section{$1.1 \quad$ Global Climate Models}

Global climate models (GCMs) use topographical data along with physical constants and parameterizations to construct numerical solutions for discretized atmospheric behavior using processes such as fluid dynamics and radiative transfer. The foundation for numerical climate models was laid throughout the 19th century with the continued development of mechanics and thermodynamics. ${ }^{1}$ One of the early attempts to apply these tools towards the goal of atmospheric predictions came from Lewis Fry Richardson, an English scientist who - while serving as a volunteer ambulance driver during World War I - sought to develop numerical solutions for regional meteorology based on initial conditions, a set of equations based on atmospheric physics, and a mechanical calculator. While the results of Richardson's efforts were cumbersome and highly unrealistic, they brought to light some of the same methods and challenges characteristic of climate models to come. The later arrival of electronic computers in the late 1940s marked a sharp increase in computational power, and efforts towards meteorological predictions resumed. Obviously, any complete GCM must include some representation of land and ocean interactions along with atmospheric dynamics, and in 1969, Syukuro Manabe published the results of such a model. ${ }^{2}$ Featuring 9 
vertical atmospheric layers, a single-layer slab ocean, and land masses represented by buckets of water, Manabe's model was able to very roughly reproduce latitudinally averaged temperature patterns at both the $500 \mathrm{mb}$ and 1,000 $\mathrm{mb}$ pressure levels (Figs. 1.1-1.2). While early versions of GCMs such as this one utilized a relatively coarse resolution which left out significant topographical features, they could still successfully reproduce many basic atmospheric trends, including annual and diurnal cycles, global circulation patterns, and rough temperature patterns.

The Community Earth System Model has been developed and supported by the National Center for Atmospheric Research since the first release of the Community Climate Model, CCM0A, in 1982. Based on earlier models, ${ }^{3}$ these versions used spectral methods of numerical integration to solve the equations of motion within the atmosphere, an approach that maximized model efficiency at the cost of mass conservation by representing trace gas concentrations and other atmospheric parameters

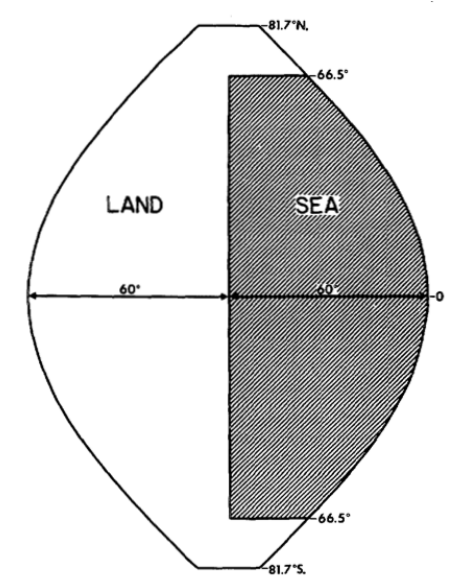

Figure 1.1: Land and ocean distribution for Manabe's 1969 coupled climate model. 


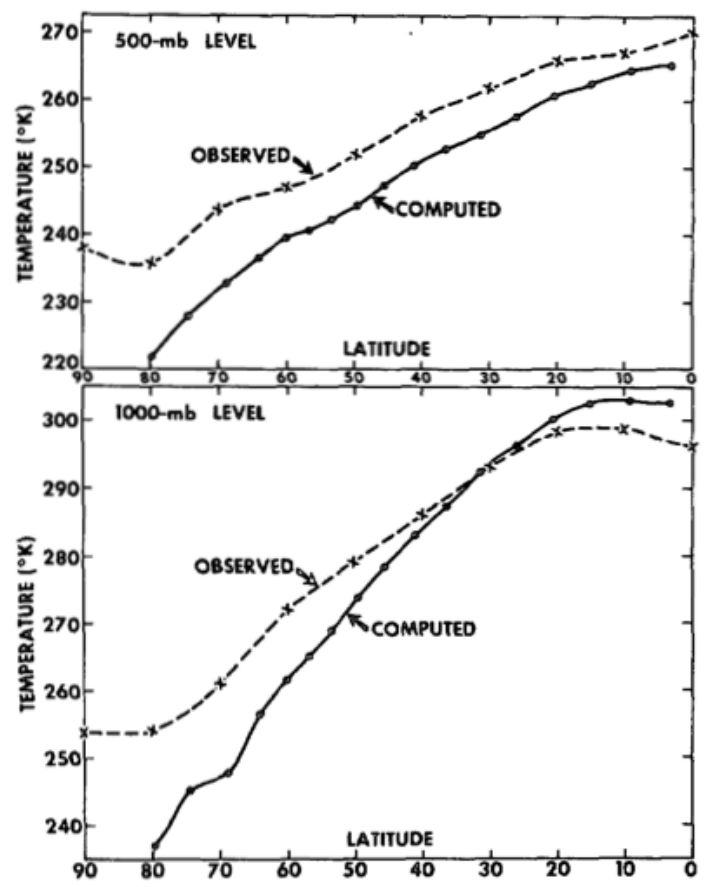

Figure 1.2: Latitudinal distributions of zonal mean temperature at $500 \mathrm{mb}$ and 1,000 $\mathrm{mb}$ levels for Manabe's 1969 model.

as sinusoidal waves. Later versions brought steady improvements, including full coupling with land, ocean, and ice models (Fig. 1.3) As resolutions steadily increased, the dynamical core also switched from the spectral Eulerian approach to a more robust finite volume scheme, improving mass conservation. The current generation of CESM includes highly customizable configurations for all individual model components. Depending on the needs of the modeler, individual components can run actively or simply report prescribed data to conserve computational efficiency. For this work, efforts were focused primarily on atmospheric effects, so only the atmospheric model (CAM) was run in an active configuration. 


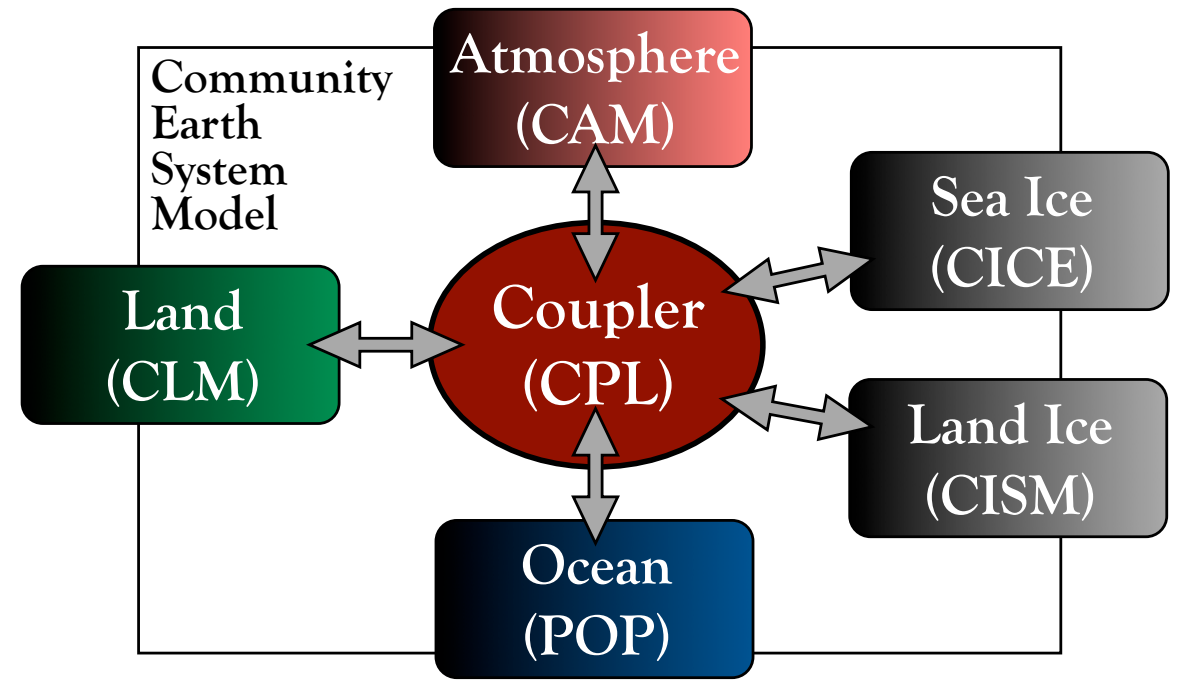

Figure 1.3: The coupled modules of CESM. Only the Community Atmosphere Model (CAM) was fully active for the cases used in this work.

\subsection{CAM: The Community Atmosphere Model}

The current version of the Community Atmosphere Model (CAM) utilizes a fixed volume dynamical core featuring a terrain-following vertical coordinate which gradually relaxes into a pressure surface at a certain elevation. ${ }^{4}$ By using this hybrid vertical coordinate, atmospheric space is discretized and turned into a collection of cells, each of which possesses an array of parameters describing its meteorological and chemical properties. The dynamics of transport are governed by established physical laws, which then allow for numerical solutions at each given time step. In addition to the basic dynamics of transport, CAM5 uses a parameterization package consisting of moist precipitation processes, clouds and radiation, a surface model, and turbulent mixing, each of which is further subdivided into smaller components. New to CAM5 is the inclusion of a cloud microphysics package to better represent cloud 
formation, aerosol interactions, and wet scavenging, as well as online, customizable chemistry packages available "out of the box". The Whole Atmosphere Community Climate Model (WACCM) option extends the default $40 \mathrm{~km}$ ceiling of CAM up to 150 $\mathrm{km}$ divided into 66 vertical layers, allowing for chemistry and transport simulations extending through the middle atmosphere and into the lower thermosphere.

\subsection{Cluster for Climate Change and Aerosol Research}

The Cluster for Climate Change and Aerosol Research (CsAR) was purchased in 2010, and performs the bulk of the modeling work done by students and researchers affiliated with Portland State University's Center for Climate and Aerosol Research (CCAR). Composed of 15 nodes equipped with 2 quad-core Xeon E5520 processors and 12 GB of RAM each, CsAR uses DDR InfiniBand to pass information between nodes during jobs and four $1 \mathrm{~TB}$ hard drives in a RAID5 array to store model input and output. Currently installed models include CESM, Goddard Earth Observing System chemistry transport model (GEOS-Chem), Weather Research and Forecasting model with chemical transport (WRF-Chem), Community Multiscale Air Quality Modeling System (CMAQ), and Model for OZone And Related chemical Tracers (MOZART). CsAR runs the CentOS Linux operating system.

\subsection{Installation of CESM}

With 15 nodes containing 8 processing cores each, CsAR is capable of completing yearly GCM runs of moderate resolution within hours, making it an ideal tool for

preliminary examinations of model performance and output. To allow CESM to 
make use of the processors in parallel, OpenMPI was installed. This message passing interface (MPI) allows the CESM code to distribute computational jobs amongst the various processing cores, dramatically improving completion times. The Network Common Data Format (NetCDF) was also installed, providing the necessary framework for the generation and parsing of this common data file format. NetCDF is widely used for large sets of scientific data, particularly within the earth sciences. These dependencies, as well as the CESM code itself, were all compiled using version 10.1.018 of Intel's C and FORTRAN compilers following the steps detailed in Appendix A. After all necessary dependencies were installed, the model itself was downloaded and installed following the instructions on page 11 of the "CESM 1.0.3 User's Guide". To port the software to CsAR, a number of initial tests were run using a generic Linux configuration, and machine-specific configuration files were then generated following the procedure outlined in Appendix B. 


\section{Chapter 2: CESM Validation and Testing}

\subsection{Model Functionality and Load Balancing}

The first step to confirming the success of the installation procedure is to verify that various types of runs can be started, stopped, resumed, and completed. To this end, a suite of diagnostic runs was assembled and completed successfully, demonstrating that the underlying model mechanisms were able to find all expected paths and dependencies. After passing these initial diagnostics, the model was tested for load balancing to determine the optimal distribution of processing cores between the various components of CESM (specific steps in Appendix B). After the ideal processor load settings were found, scripts were set up to automate the process of case configuration.

\subsection{Error Growth Test}

Another initial test of a new CESM port, an error growth comparison is a useful and efficient tool to check for major issues in the build. ${ }^{5}$ This test compares two root mean square (RMS) difference plots to highlight any major differences between the output of a new installation and a trusted one. The first plot is produced by comparing the results of the model on the new system to those generated on a previously validated system, while the second plot is generated on the previously validated system alone 
by randomly perturbing the lowest-order bits in the initial conditions. In a successful port, these two difference plots should appear very similar in both shape and order of magnitude, indicating that differences between the two ports are primarily due to roundoff errors resulting from differing compilers or machine architectures.

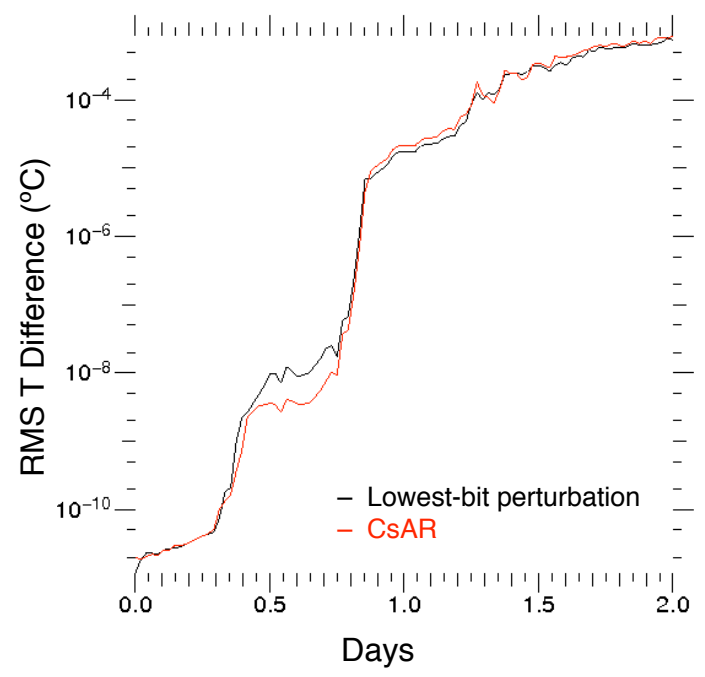

Figure 2.1: Results of CAM error growth test for CsAR. The black line indicates the difference between the control run and an identical run in which the lowest-order bits of the initial condition data were perturbed, while the red line shows the difference between the control run and the ported CsAR run. The similarity between the two suggests that differences in compiler and machine architecture are likely the primary reasons for any small differences between control and ported runs.

While a successful error growth test does not guarantee a valid port, it is a valuable first check. When it does fail, it tends to fail spectacularly, with the RMS temperature difference between the confirmed system and the new one becoming orders of magnitude larger than than the difference introduced by the lowest order bit perturbation within a matter of hours. As shown in Figure 2.1, RMS differences in temperature between the NCAR control system and the CsAR port (shown in red) were virtually 
identical to those generated by the NCAR control perturbation run (in black). This confirms that any differences between the two machines are easily explained as lowestorder bit rounding, commonly associated with differences in machine architecture or compiler versions.

\subsection{0-Year Validation Run}

The next recommended test for new ports is the 30-year validation run, in which a preindustrial, static climate is modeled for 30 years and the results averaged by year and by season. After completing the run, key benchmark variables such as temperature and pressure can be averaged, plotted, and compared to control run results. Any major problems in the port will show up as large discrepancies between the two runs in one or more of the plots. To complete this run on CsAR, a 30-year case was set up using stable preindustrial emissions and carbon nitrogen biogeochemistry. The results from the 30-year run were then averaged by latitude and elevation and compared to a set of control output generated by validated NCAR machines. Figures 2.2 and 2.3 show annual averages of several key variables for the two 30-year runs. Qualitative features match up almost perfectly between the two sets in all cases, with maximum differences of no more than $1 \%$ for all variables. The close match between these two sets of output variables confirms that the port of CESM to CsAR was a successful one. 

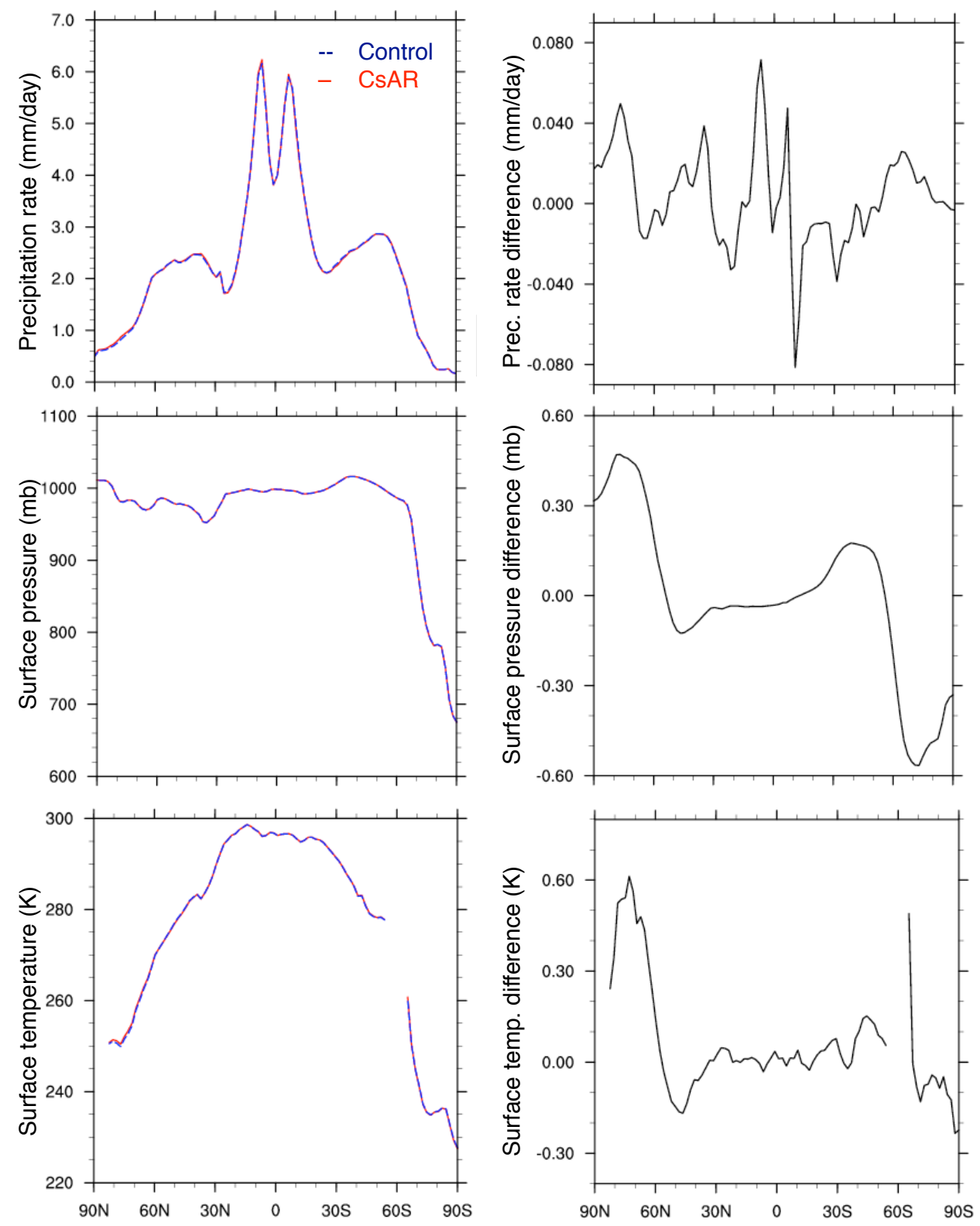

Figure 2.2: Comparison of averaged latitudinal precipitation rates (top), surface pressures (middle), and surface temperatures (bottom) for 30-year control case and ported CsAR case. Output is plotted for both runs together on the left, with absolute differences between the two on the right. 

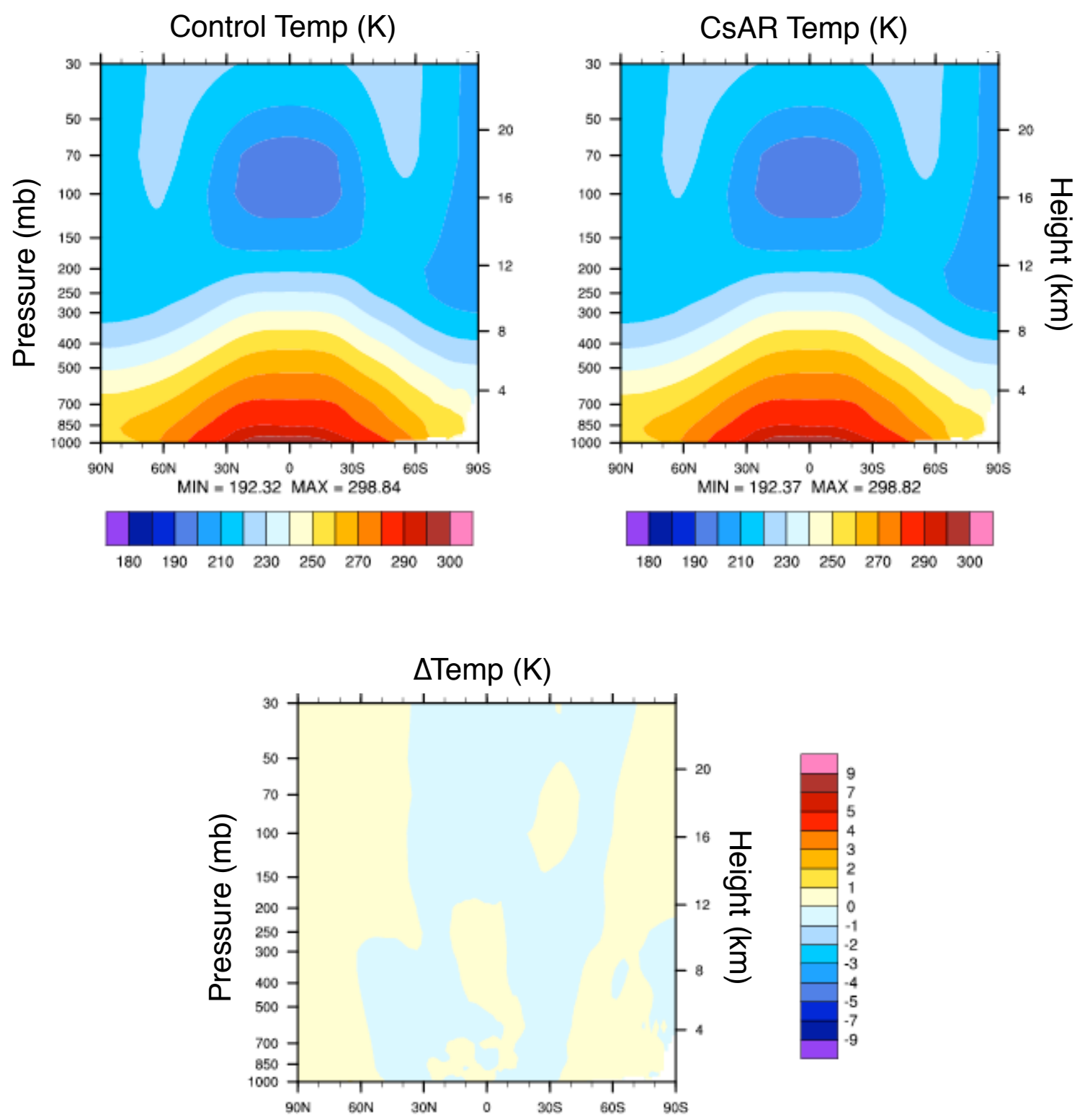

Figure 2.3: Average temperature profile comparison for 30-year control and ported cases. The reference case average (upper left) matches up almost perfectly with the ported CsAR case (upper right), as shown by the difference plot (bottom). The maximum difference between the two averaged profiles is $1.44 \mathrm{~K}$. 


\section{Chapter 3: Indirect Effect of Aerosols}

\subsection{Aerosols in CAM5}

Condensed phase optics, dealing with the impact of solid and liquid particles within the atmosphere on radiative forcing, have been included in CAM in some form since some of the earliest versions of the model. In the current default implementation, aerosols are treated modally, with three size bins used to characterize the behavior of the aerosol burden by diameter: Aitken (0.03-0.1 $\mu \mathrm{m})$, accumulation $(0.1-2.5 \mu \mathrm{m})$, and coarse $(2.5-10 \mu \mathrm{m})$. For extinction aerosol optical depth (AOD) $\tau$, single-scattering albedo $\omega$, and asymmetry parameter $g$ (a parameterization of the particles' scattering angles), aerosol optics are thus combined using

$$
\begin{aligned}
\tau_{b} & =\sum_{i=1}^{N_{a}} \tau_{i b} \\
\omega_{b} & =\sum_{i=1}^{N_{a}} \tau_{i b} \omega_{i b} / \tau_{b} \\
g_{b} & =\sum_{i=1}^{N_{a}} \tau_{i b} \omega_{i b} g_{i b} /\left(\tau_{b} \omega_{b}\right),
\end{aligned}
$$


where $\tau_{b}, \omega_{b}$, and $g_{b}$ represent the total values for the impact of all species $i$ upon bandwidth $b$. These three values can subsequently be multiplied to obtain a vertical AOD for each grid cell area, indicating the impact of the aerosol burden upon incoming shortwave radiation. However, this so-called direct effect is not the only impact of aerosols upon radiative forcing. Also important, but much more difficult to calculate, are the indirect and semidirect influences of aerosols upon cloud properties. While the semidirect effect refers to the impact of a warmer atmosphere upon the thermodynamics of cloud formation, the indirect effect addresses the importance of cloud condensation nuclei $(\mathrm{CCN})$ to cloud lifetimes and albedo. As Wilson demonstrated in $1897,{ }^{6}$ the concentration of small particles within a parcel of air can have a dramatic effect on the probability of water condensation. Very clean air can be cooled well past the saturation point without any cloud formation occurring at all, but the introduction of appropriately-sized particles into this air can trigger spontaneous condensation, causing water droplets to immediately form and consequently precipitate. With increased CCN concentration, water droplets will form sooner and in greater abundance, leading to clouds that contain more droplets of smaller average radius. With smaller droplets comes greater backscattering, according to Mie theory, which in turn causes the albedo of the cloud to increase, reflecting more incoming radiation back away from the earth's surface. Furthermore, these smaller droplets are subsequently less likely to precipitate, causing these whiter clouds to last longer. One of the major modifications made to CAM5 was the inclusion of cloud microphysics, allowing for the simulation of these changes in cloud properties based on aerosol concentrations. ${ }^{7}$ 


\subsection{Short Wave Cloud Forcing Comparison}

As a brief test of the newly ported installation of CESM, the effects of including these upgraded cloud microphysics options were examined. Using a stable preindustrial atmosphere profile (case $\mathrm{F}_{-}$1850), 10-year runs were completed using both CAM4 and CAM5 (Fig. 3.1). Similar runs then completed using a modern atmosphere profile (case F_2000), and the shortwave cloud forcing (SWCF) in the resulting model output was then examined for all cases. For CAM4, the absence of cloud microphysics means that increased aerosol concentrations have no impact on clouds, and hence on SWCF. The overall change in SWCF between preindustrial and modern atmospheres using both versions is shown in Fig. 3.2 (note that since the overall cloud forcing is negative in all cases, a positive change here corresponds to a reduction in the magnitude of the forcing effect). Globally, the weighted average of $\Delta \mathrm{SWCF}$ is +1.1 $\mathrm{W} / \mathrm{m}^{2}$ in CAM4, indicating a reduced impact of clouds in the modern case, most likely due to increased water evaporation from elevated temperatures. In CAM5, the inclusion of cloud microphysics results in a very different picture, where elevated CCN concentrations from anthropogenic emissions overpower the effect of increased temperatures, causing an increased magnitude of shortwave cloud forcing in most regions. The area-weighted average change in SWCF between preindustrial and modern atmospheres of $-1.6 \mathrm{~W} / \mathrm{m}^{2}$ for CAM5 is consistent with literature estimates in both sign and magnitude, demonstrating the importance of the new cloud microphysics treatment. ${ }^{7}$

As further evidence of the increased impact of aerosols upon cloud forcing in CAM5, the average change in SWCF for low-latitude grid cells can be compared to 
the average change in AOD, which serves as a rough proxy for local cloud-condensation nuclei. While a linear fit of the scatter plot for these two changes in CAM4 shows a positive slope with an $\mathrm{R}^{2}$ value of less than $2 \%$, in CAM5 the relationship is distinctly negative and has an increased $\mathrm{R}^{2}$ value of $14 \%$. Since the individual grid cells of GCM output are generally not independent of their neighbors due to transport effects, the statistical significance of this correlation is difficult to assess in either of these scenarios. Furthermore, AOD represents an imperfect proxy for CCN, since it does not give information on the height or size of the scattering particles (while CAM5 does provide more useful output variables on aerosols, CAM4 does not). Despite these limitations, the significantly increased strength of correlation between AOD and SWCF in CAM5 vs. CAM4 points to the impact of the cloud microphysics introduced in the upgraded version. 

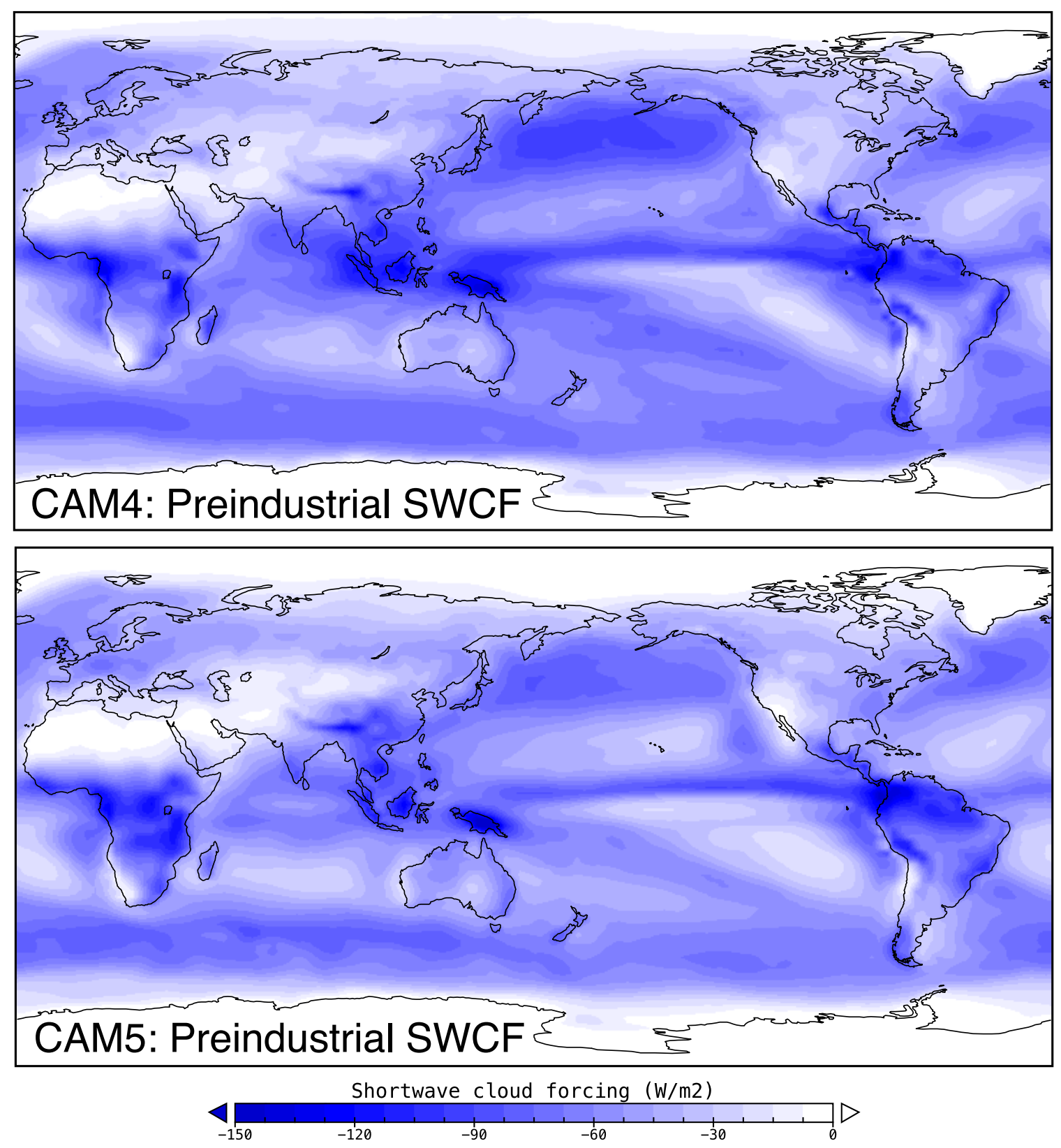

Figure 3.1: Preindustrial SWCF in CAM4 and CAM5 

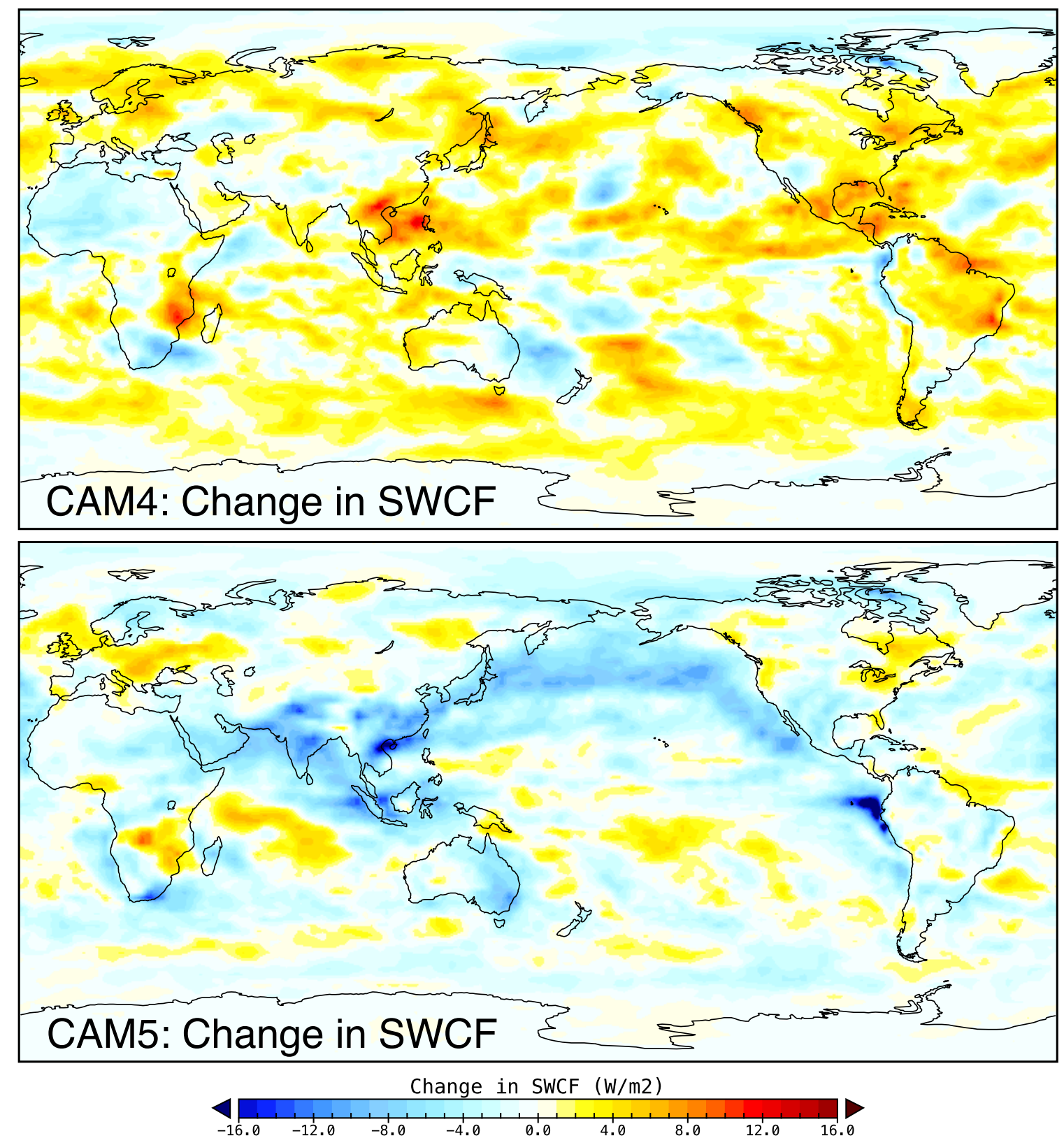

Figure 3.2: Change in SWCF (modern - preindustrial) using CAM4 and CAM5. Positive values represent a decrease in the negative forcing of local clouds, while negative values represent an increased effect. Area-weighted averages for the two versions are $1.1 \mathrm{~W} / \mathrm{m}^{2}$ in CAM4 and $-1.6 \mathrm{~W} / \mathrm{m}^{2}$ for CAM5. 

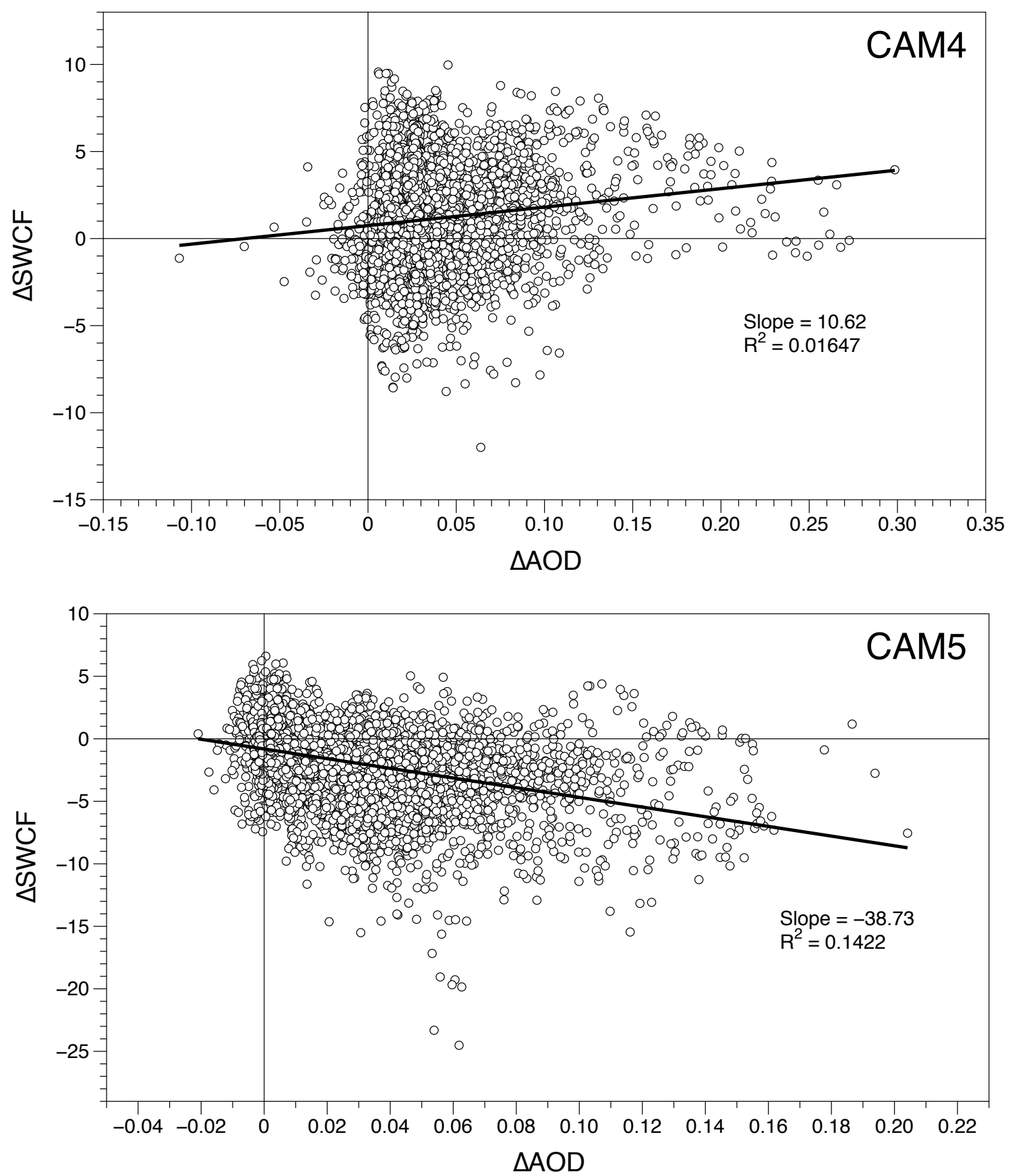

Figure 3.3: Change in SWCF vs. change in AOD using CAM4 and CAM5. Each point represents the difference between 10-year averages of modern and preindustrial atmospheres for a single grid cell between $35 \mathrm{~N}$ and $35 \mathrm{~S}$. 


\section{Chapter 4: The Impact of Methane on Ozone Loss}

\subsection{Chemistry Background}

Although stratospheric ozone $\left(\mathrm{O}_{3}\right)$ makes up a relatively tiny fraction of the total atmosphere, its presence is critical to the well-being of life on earth. Even at levels of around $0.5 \mathrm{ppm}$, stratospheric $\mathrm{O}_{3}$ absorbs a large fraction of incoming radiation in the UVC and UVB wavelengths; while UVC (100 nm - $280 \mathrm{~nm}$ ) is completely absorbed, UVB $(280 \mathrm{~nm}-315 \mathrm{~nm})$ radiation is reduced to intensities up to 100 times smaller than at the top of the atmosphere. This absorption is crucial, since these frequencies would be particularly harmful to life on earth if allowed through. In the late 20th century it was recognized that stratospheric $\mathrm{O}_{3}$ was on the decline, resulting in higher amounts of UVB radiation reaching the surface of the earth. ${ }^{8,9}$ Between 1989 and 1993, annual increases in the intensity of $300 \mathrm{~nm}$ light were measured to be $35 \%$ per year in the winter and $7 \%$ per year in the summer, with sharp decreases in stratospheric $\mathrm{O}_{3}$ identified as the primary cause. This decline had been predicted as early as 1974 based on the increasing emissions of chlorofluorocarbons (CFCs), a class of compounds whose exceptionally long lifetimes and chemical properties presented a growing threat to the $\mathrm{O}_{3}$ layer. ${ }^{10}$ With the confirmation of decreasing stratospheric 
$\mathrm{O}_{3}$ over the poles, ${ }^{11}$ much effort was put into identifying the mechanism responsible for this decline. While homogeneous processes were ruled out as possibilities, ${ }^{12}$ heterogeneous chemistry involving increased amounts of chlorine $\left(\mathrm{Cl}_{2}\right)$ within polar stratospheric clouds (PSCs) was shown to be a likely candidate, with modeled results fitting observations fairly well. ${ }^{13,14}$ During polar winters, temperatures within the isolated stratospheric vortices descend below $-80{ }^{\circ} \mathrm{C}$, allowing the formation of PSCs. The formation of the PSCs provides surface area for the following reactions involving hydrogen chloride $(\mathrm{HCl})$, chlorine nitrate $\left(\mathrm{ClONO}_{2}\right)$, and hypochlorous acid $(\mathrm{HOCl})$, to take place:

$$
\begin{aligned}
\mathrm{HCl}+\mathrm{ClONO}_{2} & \longrightarrow \mathrm{Cl}_{2}+\mathrm{HNO}_{3} \\
\mathrm{ClONO}_{2}+\mathrm{H}_{2} \mathrm{O} & \longrightarrow \mathrm{HOCl}+\mathrm{HNO}_{3} \\
\mathrm{HOCl}+\mathrm{HCl} & \longrightarrow \mathrm{Cl}_{2}+\mathrm{H}_{2} \mathrm{O}
\end{aligned}
$$

One net result of these reactions is a decrease in the reservoir species $\mathrm{HCl}$ and $\mathrm{ClONO}_{2}$, and an increase in $\mathrm{Cl}_{2}$ and $\mathrm{HOCl}$, both of which contribute via photolysis to the reactive forms of chlorine $\mathrm{ClO}$ and $\mathrm{Cl}_{2} \mathrm{O}_{2}$. These chlorine species then begin a catalytic cycle of $\mathrm{O}_{3}$ destruction through the following reactions:

$$
\begin{aligned}
& \mathrm{Cl}+\mathrm{O}_{3} \longrightarrow \mathrm{ClO}+\mathrm{O}_{2} \\
& \mathrm{ClO}+\mathrm{O} \longrightarrow \mathrm{Cl}+\mathrm{O}_{2}
\end{aligned}
$$

Through this cycle, both $\mathrm{O}_{3}$ and free oxygen atoms are reduced, with diatomic oxygen as the product. 
It has been proposed that methane $\mathrm{CH}_{4}$ can impact atmospheric $\mathrm{O}_{3}$ in several ways. First, and most directly, oxidation of $\mathrm{CH}_{4}$ in the presence of $\mathrm{NO}_{\mathrm{x}}$ is one important source of $\mathrm{O}_{3}$ at lower altitudes; therefore, changes in $\mathrm{CH}_{4}$ concentrations can impact $\mathrm{O}_{3}$ concentrations via

$$
\begin{gathered}
\mathrm{CH}_{4}+\mathrm{OH} \longrightarrow \mathrm{CH}_{3}+\mathrm{H}_{2} \mathrm{O} \\
\mathrm{CH}_{4}+\mathrm{O}\left({ }^{1} \mathrm{D}\right) \longrightarrow \mathrm{CH}_{3}+\mathrm{OH} \\
\mathrm{CH}_{3}+\mathrm{O}_{2}+\mathrm{M} \longrightarrow \mathrm{CH}_{3} \mathrm{O}_{2}+\mathrm{M} \\
\mathrm{CH}_{3} \mathrm{O}_{2}+\mathrm{NO} \longrightarrow \mathrm{CH}_{3} \mathrm{O}+\mathrm{NO}_{2} \\
\mathrm{NO}_{2} \stackrel{h \nu}{\longrightarrow} \mathrm{NO}+\mathrm{O} \\
\mathrm{O}+\mathrm{O}_{2}+\mathrm{M} \longrightarrow \mathrm{O}_{3}+\mathrm{M}
\end{gathered}
$$

Furthermore, $\mathrm{CH}_{4}$ can compete for reactions with chlorine, acting as a buffer for $\mathrm{O}_{3}$ and thereby increasing its lifetime. ${ }^{15}$ On the other hand, stratospheric $\mathrm{CH}_{4}$ leads to increased $\mathrm{OH}$ and $\mathrm{HO}_{2}$, both of which were identified early on as catalytic contributors to ozone depletion through reactions similar to those described for $\mathrm{Cl}$ above:

$$
\begin{aligned}
& \mathrm{OH}+\mathrm{O}_{3} \longrightarrow \mathrm{HO}_{2}+\mathrm{O}_{2} \\
& \mathrm{HO}_{2}+\mathrm{O} \longrightarrow \mathrm{OH}+\mathrm{O}_{2}
\end{aligned}
$$

It has also been suggested that increased $\mathrm{CH}_{4}$ levels at the poles could lead to an increase of stratospheric water vapor through oxidation, which would then assist the decomposition of winter $\mathrm{O}_{3}$ through an increase in PSCs. ${ }^{16}$ 


\subsection{WACCM Cases}

To examine and quantify the total impact of $\mathrm{CH}_{4}$ on global $\mathrm{O}_{3}$ levels, several runs were set up using the Whole Atmosphere Community Climate Model (WACCM) option within CESM as shown in Table 4.1. With vertical levels as high as $150 \mathrm{~km}$ above the surface, WACCM allows for simulations of stratospheric chemistry, which is beyond the spatial scope of other CESM cases. While the $\mathrm{O}_{3}$ column output used in this study includes all atmospheric levels, the vast majority of $\mathrm{O}_{3}(85 \%$ $95 \%$ ) is stratospheric, ${ }^{17}$ making the raw $\mathrm{O}_{3}$ column figures representative primarily of stratospheric concentrations. Two levels of CFC burdens were used, one in which CFCs were completely absent, and one with CFCs at year 2000 levels. Four levels of atmospheric $\mathrm{CH}_{4}$ were also generated, including $\mathrm{CH}_{4}$ at preindustrial, modern, $150 \%$ modern, and $200 \%$ modern levels. Each case was initially run for seven years, and then extended for three more years if average $\mathrm{O}_{3}$ levels had not stabilized by that

Table 4.1: WACCM Run Descriptions

All cases begin with a year 2000 atmosphere, and then have initial conditions and lower boundary conditions modified as necessary. For preindustrial $\mathrm{CH}_{4}$ cases, surface levels were set to $45 \%$ of their modern values. Low and high projected increases were based on IPCC ranges for potential $\mathrm{CH}_{4}$ increases; the low $\mathrm{CH}_{4}$ projection represents a $50 \%$ increase, while the high projection represents a doubling of $\mathrm{CH}_{4}$. Cases without $\mathrm{CFCs}$ also included a reduction in $\mathrm{N}_{2} \mathrm{O}$ to preindustrial levels, $84 \%$ of their modern values.

\begin{tabular}{lcc} 
Case Name & $\mathrm{CH}_{4}$ Level & CFCs Present \\
\hline P0 & Preindustrial & No \\
P1 & Preindustrial & Yes \\
M0 & Modern & No \\
M1 & Modern & Yes \\
L0 & Low Projected Increase & No \\
H0 & High Projected Increase & No
\end{tabular}


time, with stability defined as less than $1 \%$ change in the area-weighted $\mathrm{O}_{3}$ burden for 5 consecutive years. After this process was completed, the final 4 years of each case were averaged and analyzed. Note that the averaged years are taken from a stable equilibrium state of repeated conditions rather than an ensemble of unique years and forcings, making standard deviation calculations artificially low and essentially meaningless. For this reason they are not included on the following figures. Running an ensemble of many perturbed cases would give a greater indication of the variability that could be expected from these results, and would make an ideal extension of this work.

Globally averaged $\mathrm{O}_{3}$ burdens for four cases with varying $\mathrm{CH}_{4}$ and CFCs (Fig. 4.1) show that the net impact of $\mathrm{CH}_{4}$ on $\mathrm{O}_{3}$ is negative, while the net impact of $\mathrm{CH}_{4}$ is positive. Examining these changes by elevation shows that the bulk of $\mathrm{O}_{3}$ loss due to CFCs occurs in the stratosphere between $10 \mathrm{~km}$ and $40 \mathrm{~km}$ (Fig. $4.2 \mathrm{~A}$ ), where the difference between high and low $\mathrm{CH}_{4}$ is also the most pronounced. In the absence of CFCs, increased $\mathrm{CH}_{4}$ emissions primarily affect surface $\mathrm{O}_{3}$, with a reduced impact at stratospheric elevations (Fig. 4.2B). In the troposphere, increased $\mathrm{O}_{3}$ is probably a result of reactions with $\mathrm{NO}_{\mathrm{x}}$, as shown in Eqn. 4.3 above. In the stratosphere, the decrease in $\mathrm{O}_{3}$ above $40 \mathrm{~km}$ is likely a result of increased $\mathrm{HO}_{\mathrm{x}}$ introduced by the $\mathrm{CH}_{4}$ (Eqn. 4.4), while the increase in $\mathrm{O}_{3}$ in the lower stratosphere is partially explained by the increased UV radiation reaching those lower altitudes due to the thinning $\mathrm{O}_{3}$ layer above. While these results are similar to those found in other studies, ${ }^{18}$ the net increase of stratospheric $\mathrm{O}_{3}$ is somewhat surprising in an atmosphere without CFCs - more work should be done to assess whether this increase is due to interactions with some other species. When CFCs are present, the positive stratospheric impact 
becomes far more pronounced, with the increased competition for $\mathrm{Cl}$ provided by the $\mathrm{CH}_{4}$ buffering the destruction of $\mathrm{O}_{3}$.

Latitudinal profiles for the four different $\mathrm{CH}_{4}$ levels modeled (Fig. 4.3A) show a positive correlation between $\mathrm{O}_{3}$ and $\mathrm{CH}_{4}$ at all latitudes, though the effect becomes less pronounced at the higher $\mathrm{CH}_{4}$ levels. Comparing latitudinal output for cases with and without CFCs (Fig. 4.3B) show the strong negative impact of these compounds, especially around the South Pole. Of particular note is the large difference in $\mathrm{O}_{3}$ between the $\mathrm{M} 1$ case and the $\mathrm{P} 1$ case in the antarctic region when compared to the corresponding M0 and P0 cases, suggesting that the buffering effect of $\mathrm{CH}_{4}$ on stratospheric $\mathrm{O}_{3}$ in the presence of CFCs is especially enhanced in this area. The significance of $\mathrm{CH}_{4}$ levels as a buffer for stratospheric $\mathrm{O}_{3}$ around Antarctica in particular is evidenced again in global maps of the impact of CFCs on total $\mathrm{O}_{3}$ column levels, (Fig. 4.4), where the enhanced negative changes are readily apparent in the preindustrial $\mathrm{CH}_{4}$ case. Likewise, while the change to modern $\mathrm{CH}_{4}$ in the absence of CFCs shows a relatively uniform global distribution, in the presence of CFCs the effect becomes stronger and more concentrated (Fig. 4.5). By subtracting the values showing the impact of $\mathrm{CH}_{4}$ with CFCs from those without, an estimate for the total $\mathrm{O}_{3}$ "protected" from CFCs by the increased $\mathrm{CH}_{4}$ can be generated (Fig. 4.6). Global area-weighted averages of these results show that approximately $1.3 \%$ of preindustrial $\mathrm{O}_{3}$ was protected from destruction by the increase to modern $\mathrm{CH}_{4}$ levels, a significant value considering the estimated $6 \%$ decrease per decade associated with CFC emissions during the late 20th century. ${ }^{19}$

Because of the computational cost of running WACCM, a relatively low horizontal resolution of $4^{\circ}$ was initially chosen for this work. To check possible sensitivity to 
model resolution, one of the cases was repeated at a $2^{\circ}$ resolution, and the latitudinal averages of the two sets of output were compared (Fig. 4.7). Based on the overall similarity of the results and the computational costs of the higher resolution runs, it was decided that $4^{\circ}$ was sufficient for this work, despite the difference in $\mathrm{O}_{3}$ output at higher latitudes. An extension of this study with more runs at higher resolutions could further test the validity of the coarse resolution results.

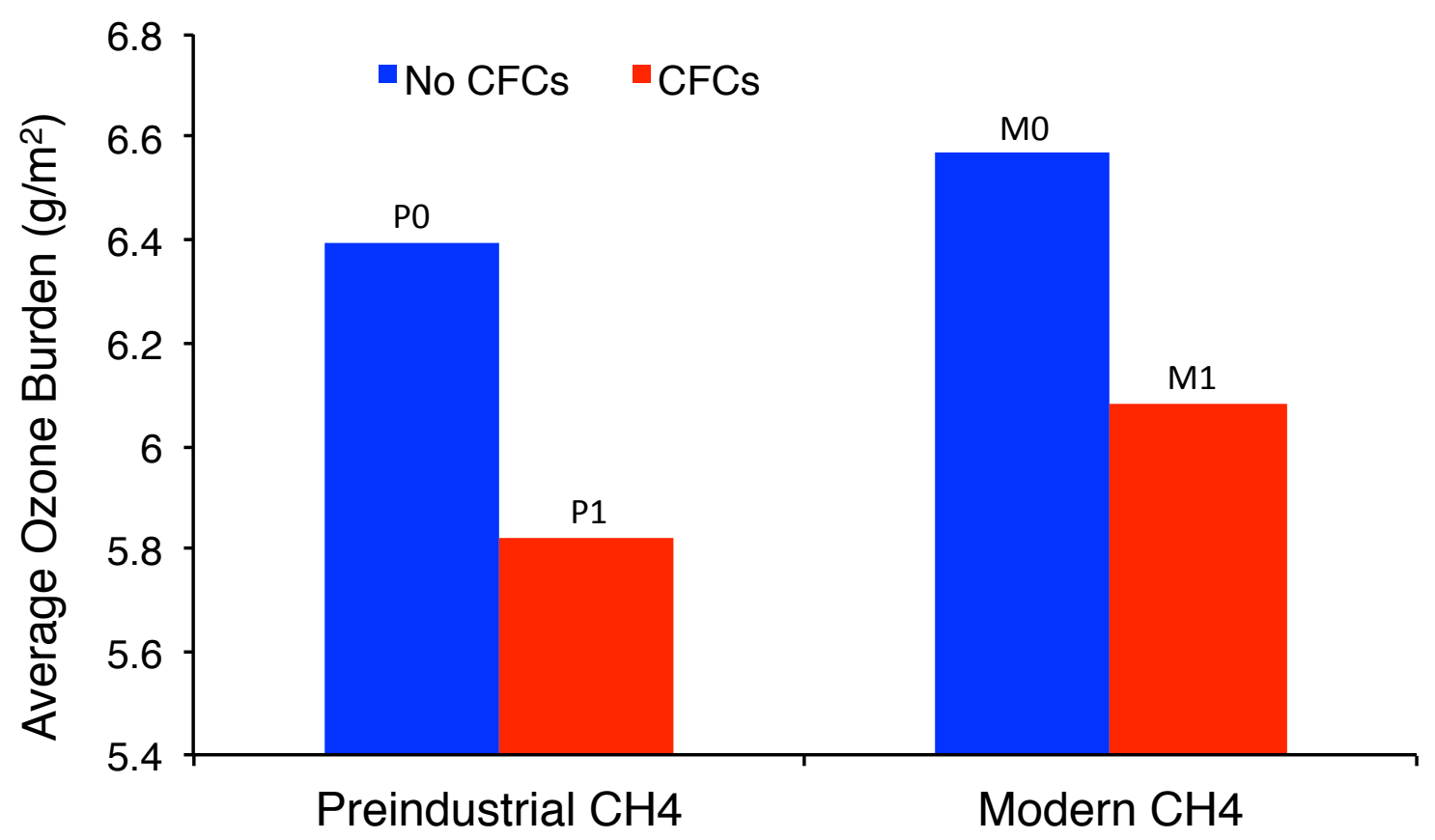

Figure 4.1: Average $\mathrm{O}_{3}$ column at equilibrium for 4 primary cases (note that y-axis does not begin at 0 , to highlight differences). Here, the impact of CFCs upon global $\mathrm{O}_{3}$ is shown for both preindustrial and modern $\mathrm{CH}_{4}$ levels. The drop in $\mathrm{O}_{3}$ with the addition of CFCs is approximately $0.58 \mathrm{~g} / \mathrm{m}^{2}$ for the preindustrial case and $0.49 \mathrm{~g} / \mathrm{m}^{2}$ for the modern $\mathrm{CH}_{4}$ case. 

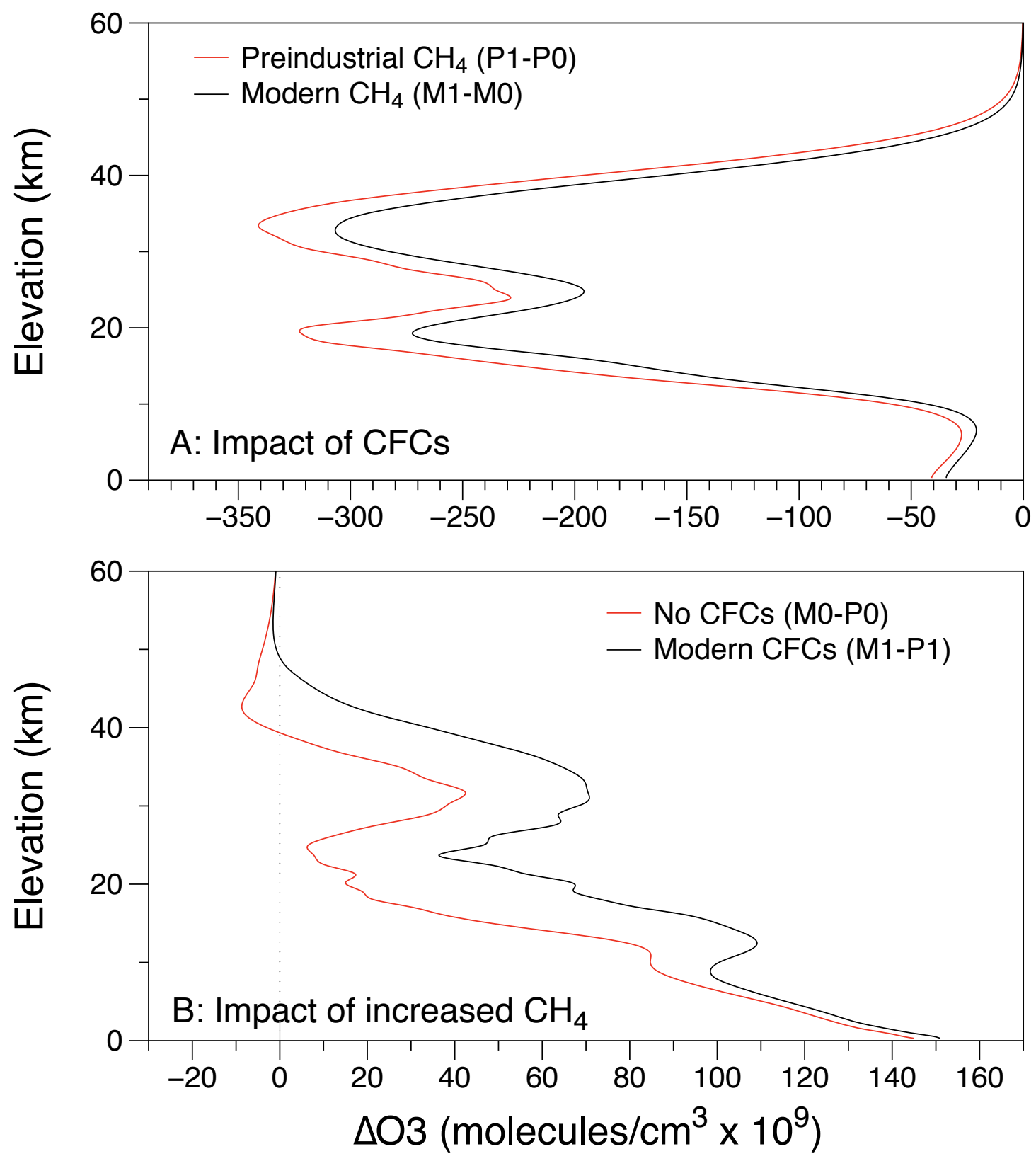

Figure 4.2: Change in $\mathrm{O}_{3}$ density vertical profile with addition of CFCs (M1 - M0 and P1 - P0, above), and increase to modern $\mathrm{CH}_{4}$ (M1 - P1 and M0 - P0, below). Values are averaged globally by elevation. Note that while the lower figure reveals that increasing $\mathrm{CH}_{4}$ has a significant effect on tropospheric $\mathrm{O}_{3}$, the difference between the CFC case and non-CFC case at these lower elevations is minimal. 

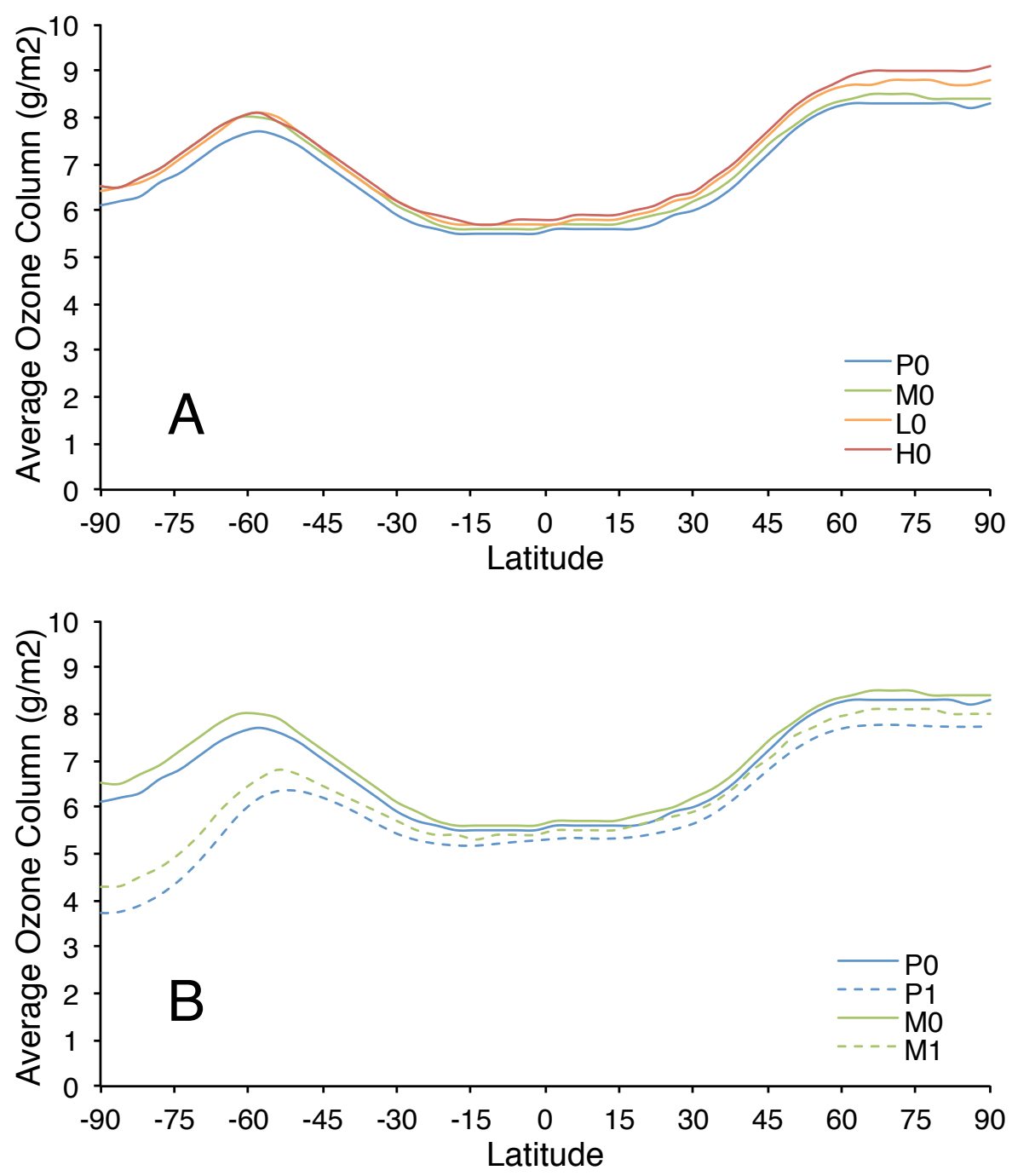

Figure 4.3: Latitudinal $\mathrm{O}_{3}$ profiles by case, showing results of varying $\mathrm{CH}_{4}$ levels (A) as well as varying $\mathrm{CFCs}(\mathrm{B})$. Line color indicates $\mathrm{CH}_{4}$ level (increasing as the color shifts from blue to red) while dashed lines indicate runs with CFCs. 

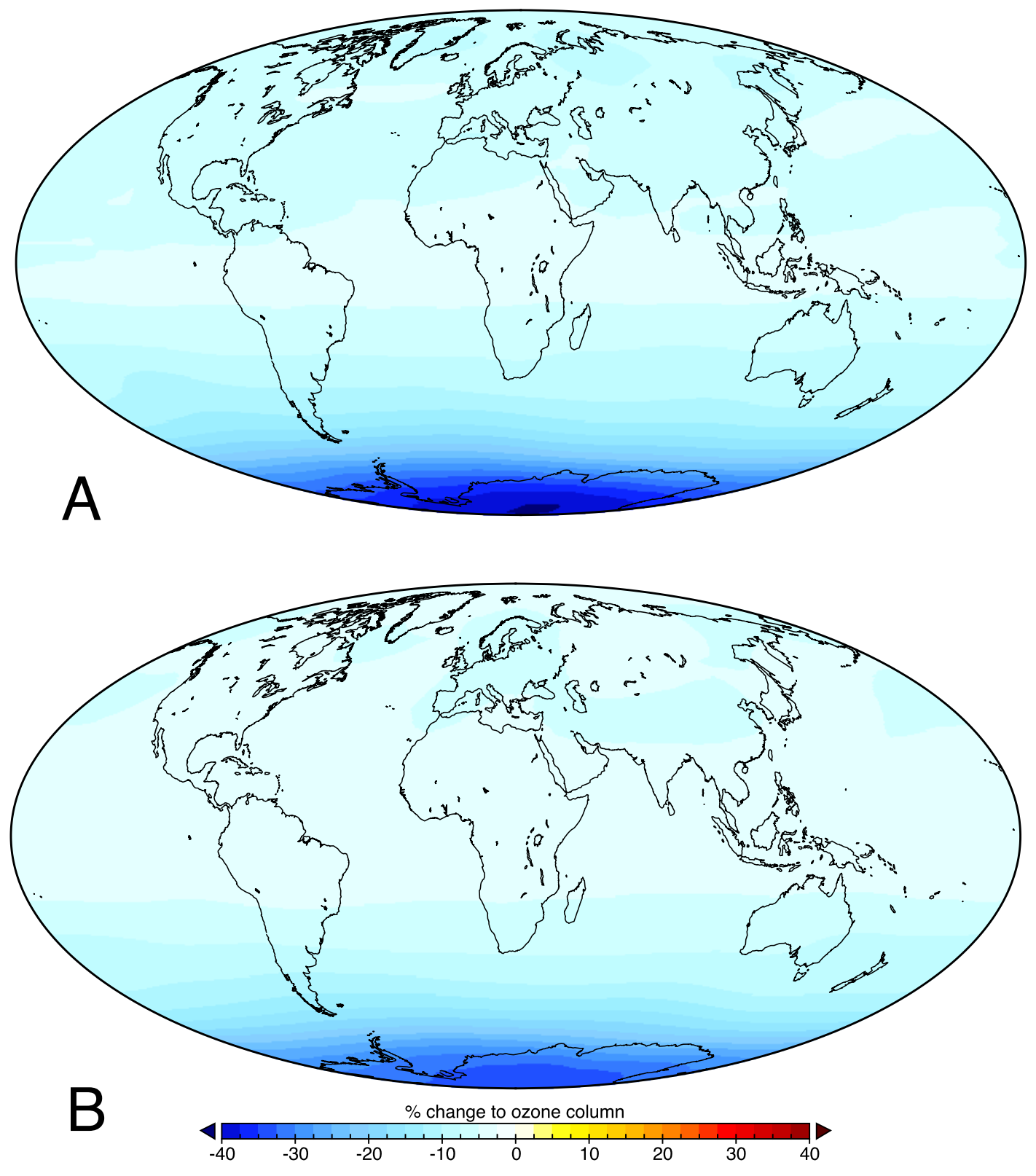

Figure 4.4: Impact of $\mathrm{CFCs}$ on $\mathrm{O}_{3}$ column at preindustrial $\mathrm{CH}_{4}$ levels ( $\mathrm{P} 1-\mathrm{P} 0$, above), and at modern $\mathrm{CH}_{4}$ levels (M1 - M0, below). The maximum decrease in the preindustrial $\mathrm{CH}_{4}$ case is $40 \%$, while the maximum decrease in the modern $\mathrm{CH}_{4}$ case is $34 \%$. 

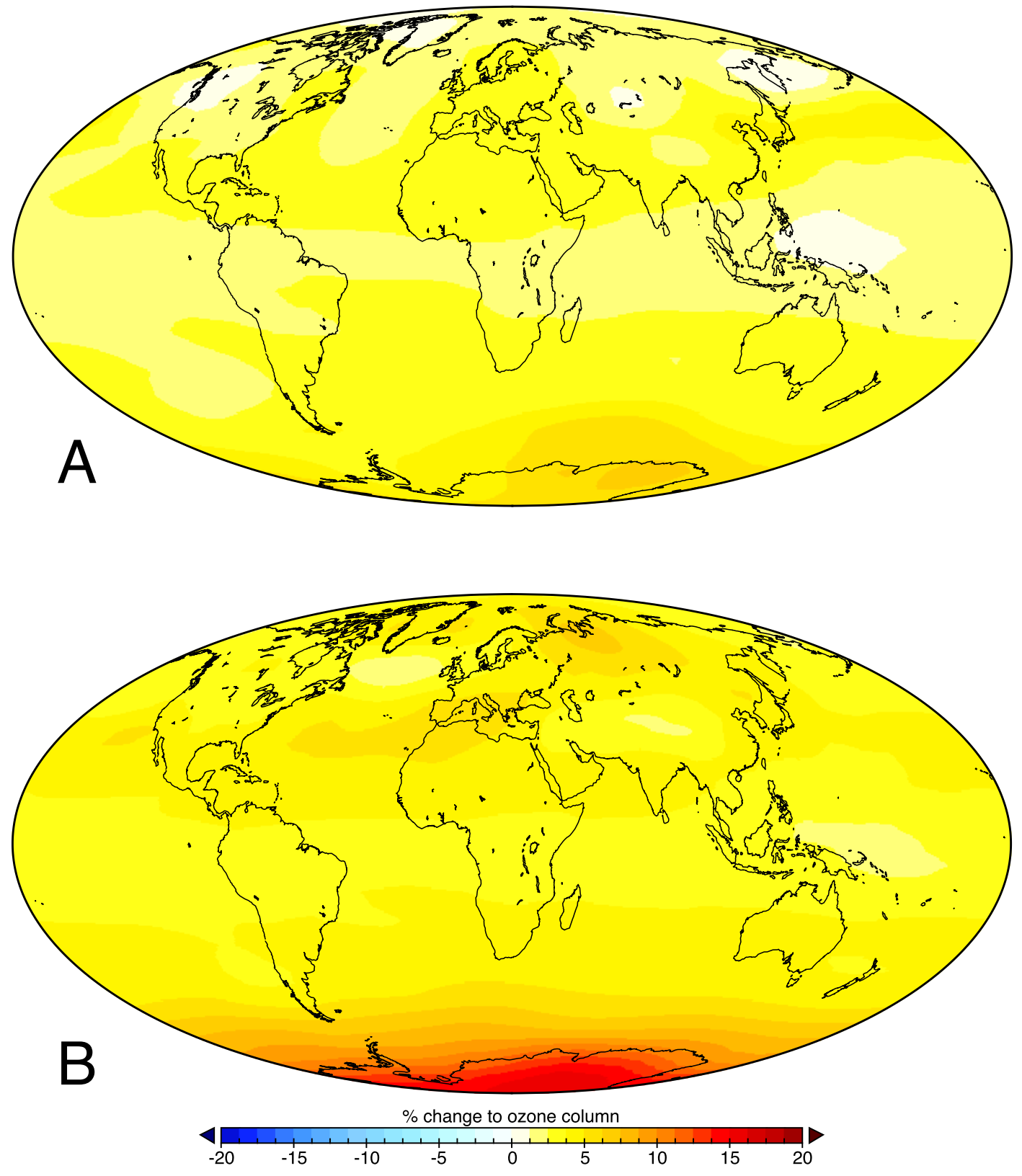

Figure 4.5: Impact of $\mathrm{CH}_{4}$ on $\mathrm{O}_{3}$ column without CFCs (M0 - P0, above), and with CFCs (M1 - P1, below). The maximum increase without CFCs is $7 \%$, while the maximum increase with CFCs is $16 \%$. 


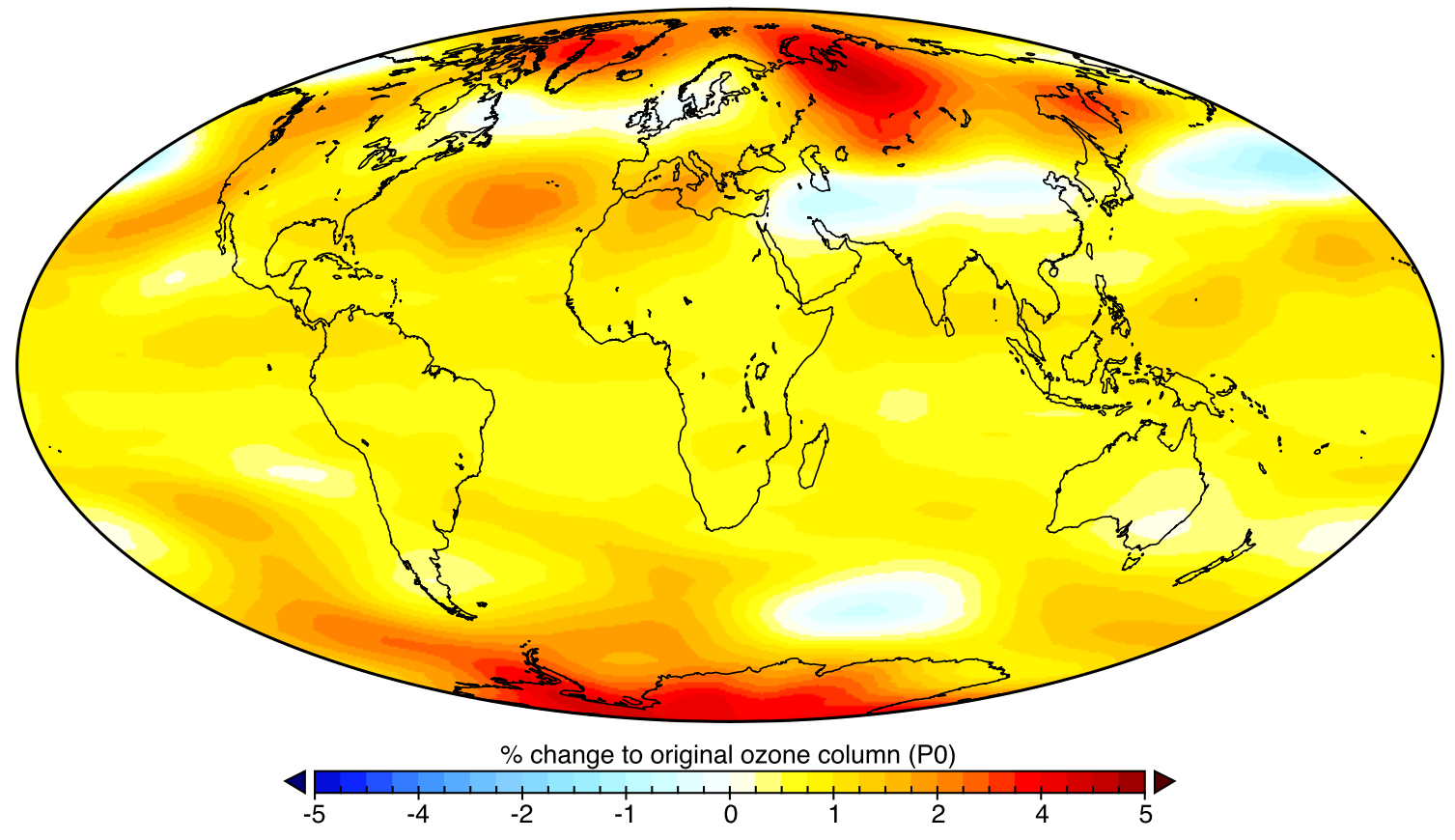

Figure 4.6: Amount of $\mathrm{O}_{3}$ "protected" from CFCs by increase to modern $\mathrm{CH}_{4}$. $((\mathrm{M} 1-\mathrm{M} 0)-(\mathrm{P} 1-\mathrm{P} 0))$ 


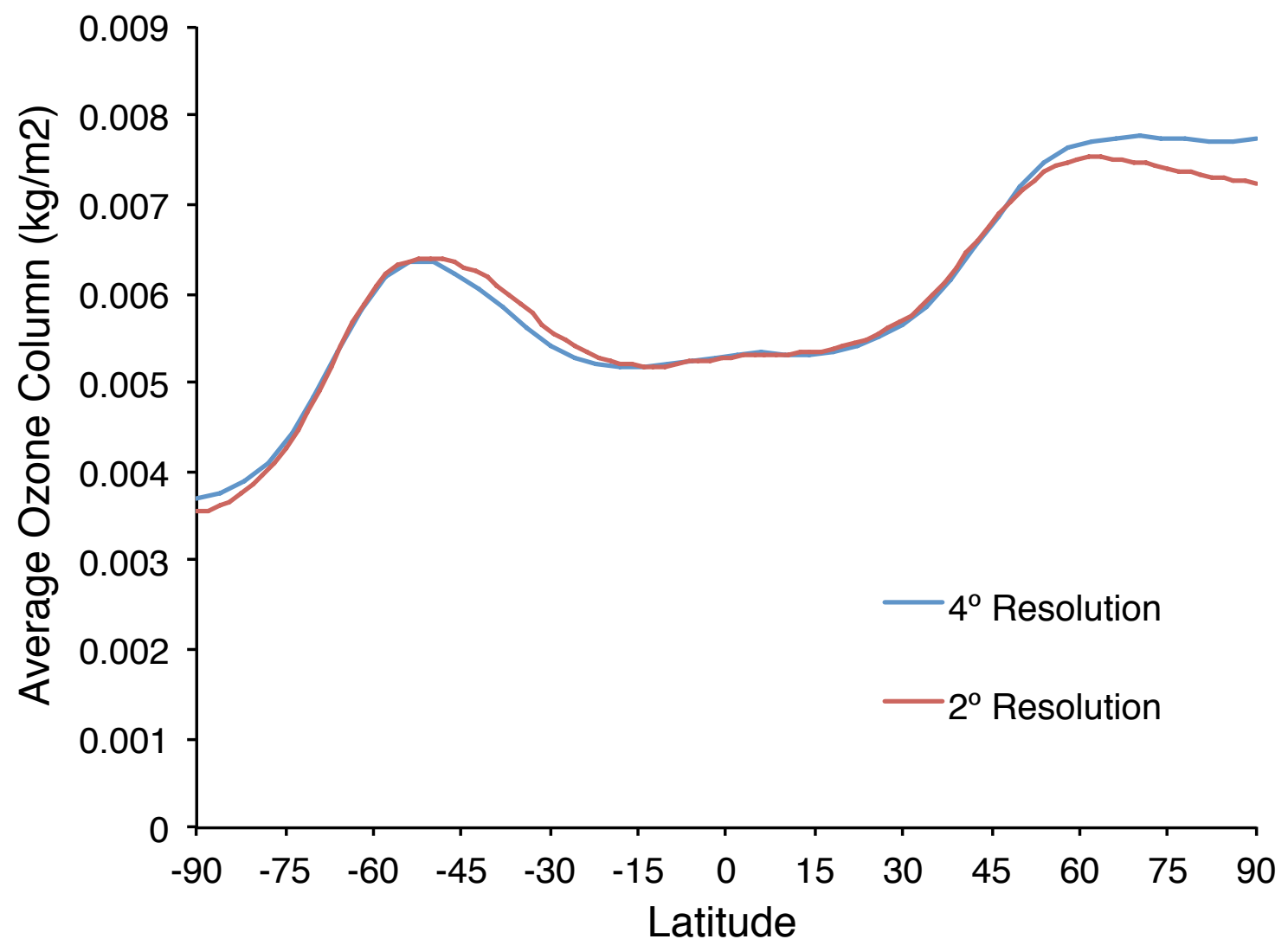

Figure 4.7: Latitudinal averages of equilibrium $\mathrm{O}_{3}$ column at fine and coarse model resolutions. Since agreement is quite good at all but the highest latitudes, coarser resolution runs were used for this study. 


\section{Chapter 5: Conclusions}

\subsection{CESM Ported Successfully to PSU Research Cluster}

The CsAR port of CESM has proven stable and productive. The successful perturbation error growth test showed that differences between CsAR's results and those of the control machine differ by an amount easily attributable to the rounding of the lowest bit of the initial conditions. Applying the CsAR port of CESM to a comparison of shortwave cloud forcing changes both with and without the recently added cloud microphysics produced results that are in line with expectations. Without the inclusion of indirect aerosol effects modern atmosphere simulations actually show a very slight reduction in shortwave cloud forcing compared to a preindustrial case, while including indirect aerosol effects produces an overall increase in shortwave cloud forcing magnitude equivalent to an area-weighted $1.63 \mathrm{~W} / \mathrm{m}^{2}$, a value consistent with current literature approximations.

\subsection{Buffering Effect of Increased Methane on Stratospheric Ozone}

An array of runs varying CFC and methane levels was planned and implemented to examine the buffering effect of increased methane levels on CFC-caused $\mathrm{O}_{3}$ depletion. After testing sensitivity to resolution, $4^{\circ}$ WACCM runs were completed for various 
atmospheric scenarios. The addition of CFCs produced the expected drop in global $\mathrm{O}_{3}$ burden, especially over the poles, while increased methane tended to increase $\mathrm{O}_{3}$. The magnitude of this boost to $\mathrm{O}_{3}$ was significantly higher in atmospheres containing CFCs, with competition for the chlorine radical protecting approximately $1.3 \%$ of preindustrial $\mathrm{O}_{3}$ from destruction. Although the buffering role of methane within the stratosphere has been predicted and described previously, these results represent the first attempt to quantify the amount of additional $\mathrm{O}_{3}$ that would have been lost with the rise of CFCs if methane levels had been lower. 


\section{Bibliography}

[1] W.M. Washington and C.L. Parkinson. An introduction to three-dimensional climate modeling. Univ Science Books, 1986.

[2] S. Manabe. Climate and the ocean circulation. Monthly Weather Review, 97(11):739-774, 1969.

[3] W. Bourke, B. McAvaney, K. Puri, and R. Thurling. Global modeling of atmospheric flow by spectral methods. General circulation models of the atmosphere.(A 78-10662 01-47) New York, Academic Press, Inc., page 267-324, 1977.

[4] A. Kasahara. Various vertical coordinate systems used for numerical weather prediction. Monthly Weather Review, 102(7):509-522, 1974.

[5] J. M Rosinski and D. L Williamson. The accumulation of rounding errors and port validation for global atmospheric models. SIAM Journal on Scientific Computing, 18:552, 1997.

[6] C. T. R. Wilson. Condensation of water vapour in the presence of Dust-Free air and other gases. Proceedings of the Royal Society of London, 61(369-377):240, 1897. 
[7] M. Wang, S. Ghan, M. Ovchinnikov, X. Liu, R. Easter, E. Kassianov, Y. Qian, and H. Morrison. Aerosol indirect effects in a multi-scale aerosol-climate model PNNL-MMF. Atmospheric Chemistry and Physics, 11(11):5431-5455, 2011.

[8] Ralph J. Cicerone. Changes in stratospheric ozone. Science, 237(4810):35 -42, July 1987.

[9] J. B. Kerr and C. T. McElroy. Evidence for large upward trends of ultraviolet-B radiation linked to ozone depletion. Science, 262(5136):1032, 1993.

[10] M. J Molina and F. S Rowland. Chlorine atom-catalysed destruction of ozone. Nature, 249:810-812, 1974.

[11] JC Farman, BG Gardiner, and JD Shanklin. Large losses of total ozone in antarctica reveal seasonal ClOx/NOx interaction. Nature, 315:207-210, 1985.

[12] Susan Solomon, Rolando R. Garcia, F. Sherwood Rowland, and Donald J. Wuebbles. On the depletion of antarctic ozone. Nature, 321(6072):755-758, June 1986.

[13] M. B McElroy, R. J Salawitch, S. C Wofsy, and J. A Logan. Reductions of antarctic ozone due to synergistic interactions of chlorine and bromine. Nature, 321(6072):759-762, 1986.

[14] J. G. Anderson, D. W. Toohey, and W. H. Brune. Free radicals within the antarctic vortex: The role of CFCs in antarctic ozone loss. Science, 251(4989):39 -46, January 1991. 
[15] L. K. Randeniya, P. F. Vohralik, and I. C. Plumb. Stratospheric ozone depletion at northern mid latitudes in the 21 st century- the importance of future concentrations of greenhouse gases nitrous oxide and methane. Geophysical research letters, 29(4):10-1, 2002.

[16] D. R Blake and F. S Rowland. Continuing worldwide increase in tropospheric methane, 1978 to 1987. Science, 239(4844):1129, 1988.

[17] J. Fishman and E.V. Browell. Comparison of satellite total ozone measurements with the distribution of tropospheric ozone obtained by an airborne uv-dial system over the amazon basin. Tellus B, 40(5):393-407, 1988.

[18] JF Lamarque, JT Kiehl, CA Shields, BA Boville, and DE Kinnison. Modeling the response to changes in tropospheric methane concentration: Application to the permian-triassic boundary. Paleoceanography, 21(3):PA3006, 2006.

[19] WMO. Scientific assessment of ozone depletion: 2006. World Meteorological Organisation, Global Ozone Research and Monitoring Project-Report, 50:572, 2007. 


\section{Appendix A: CESM Dependencies}

\section{OpenMPI}

OpenMPI is an open source message passing interface, allowing the cluster's head node to distribute the load of running CESM amongst each of the involved working nodes. Intel compilers were again used to compile and install version 1.2.8 of the OpenMPI software, which was downloaded from <http://www.open-mpi.org $>$.

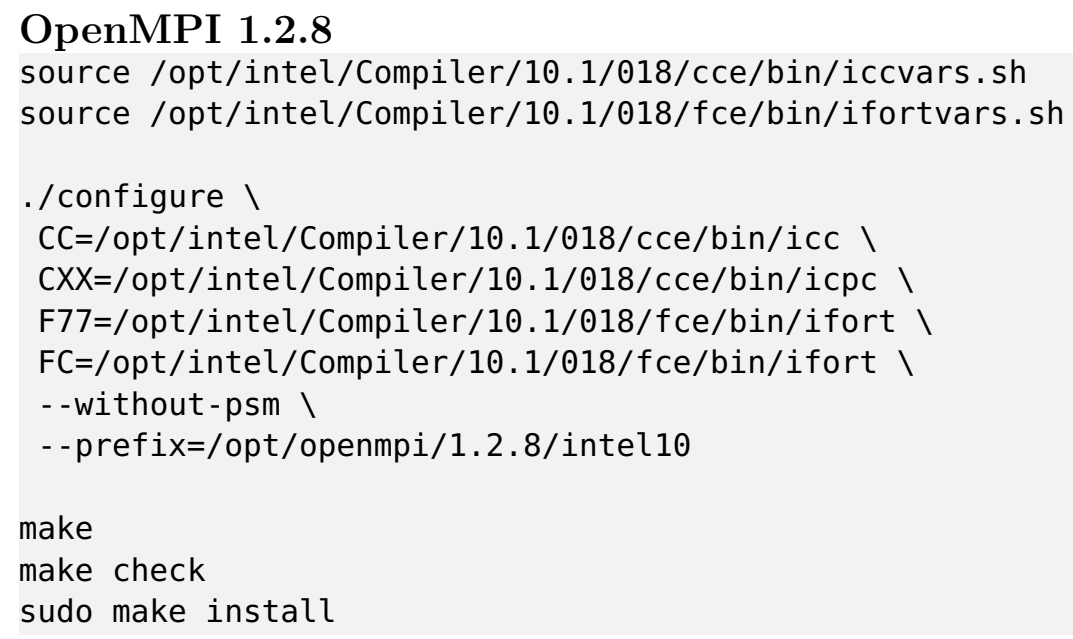

OpenMPI 1.2.8 Environment Variables

PATH /act/openmpi/intel/bin

MANPATH /act/openmpi/intel/share/man

LD_LIBRARY_PATH /act/openmpi/intel/lib 


\section{NetCDF}

NetCDF (network Common Data Form) is a common format for scientific data, and is characterized by portable, self-describing files which can be created, opened, and modified by a wide range of utilities. Version 3.6.3 of netCDF was installed, along with a module for easy environmental variable configuration. Installation files were downloaded from <http://www.unidata.ucar.edu/software/netcdf/ > .

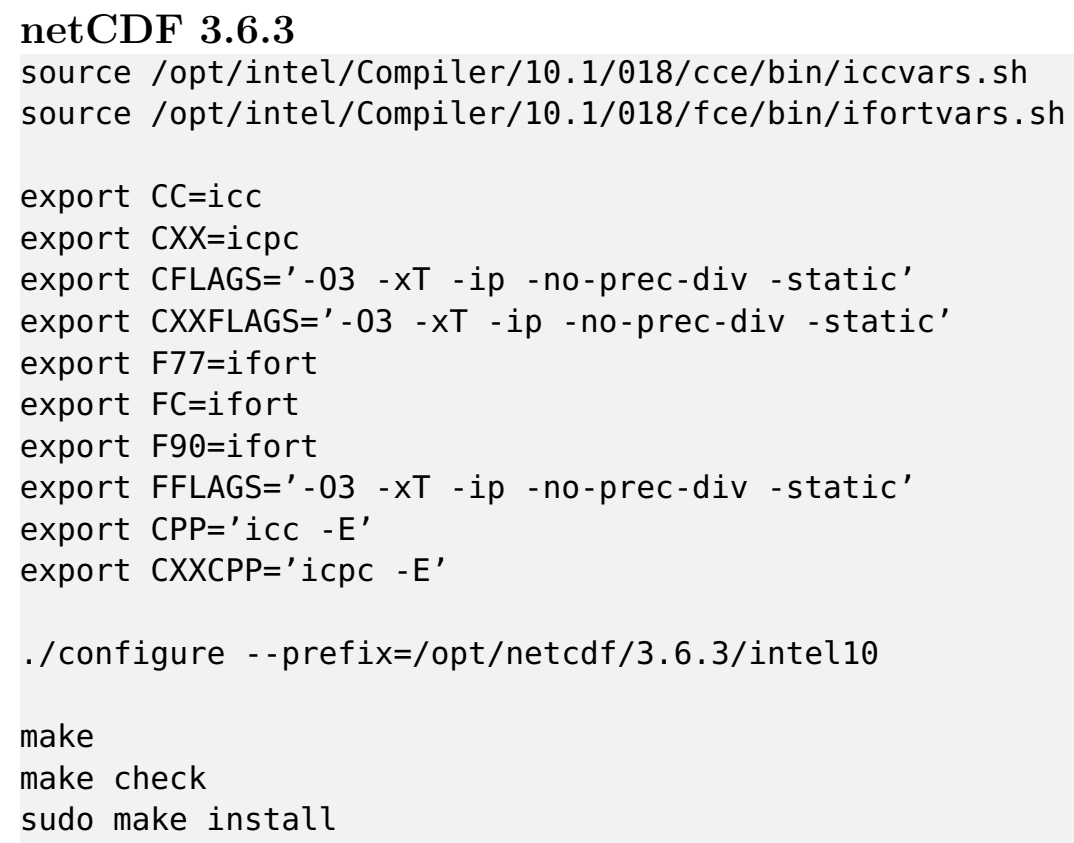




\section{Appendix B: CESM Porting and Operation}

Before CESM is run on a new system, machine-specific configuration files must be generated. To this end, three custom configuration files - Macros.caesar, mkbatch.caesar, and env_machopts.caesar - were developed by modifying the generic files provided. Differences between the generic machine files and custom CsAR files are summarized in the following diff output. The custom files can be recreated either by hand or by using the 'patch' command along with the installation information provided here.

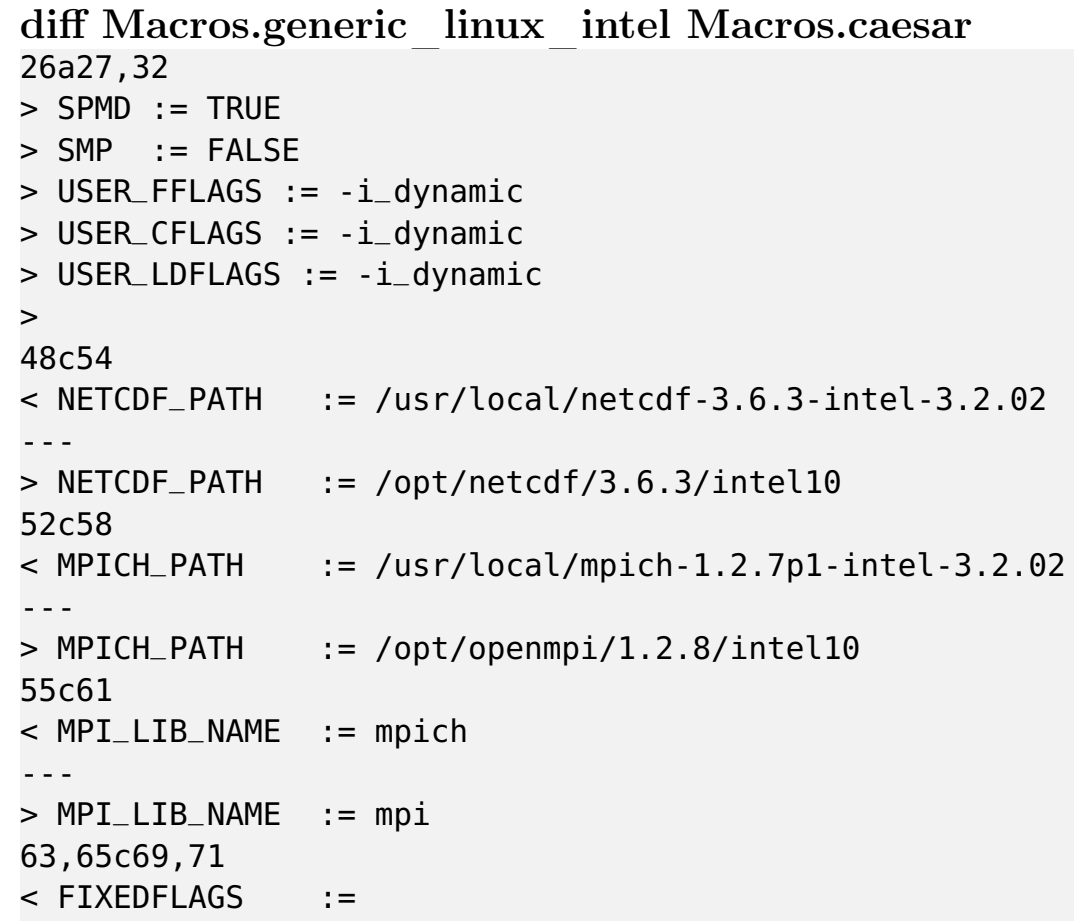




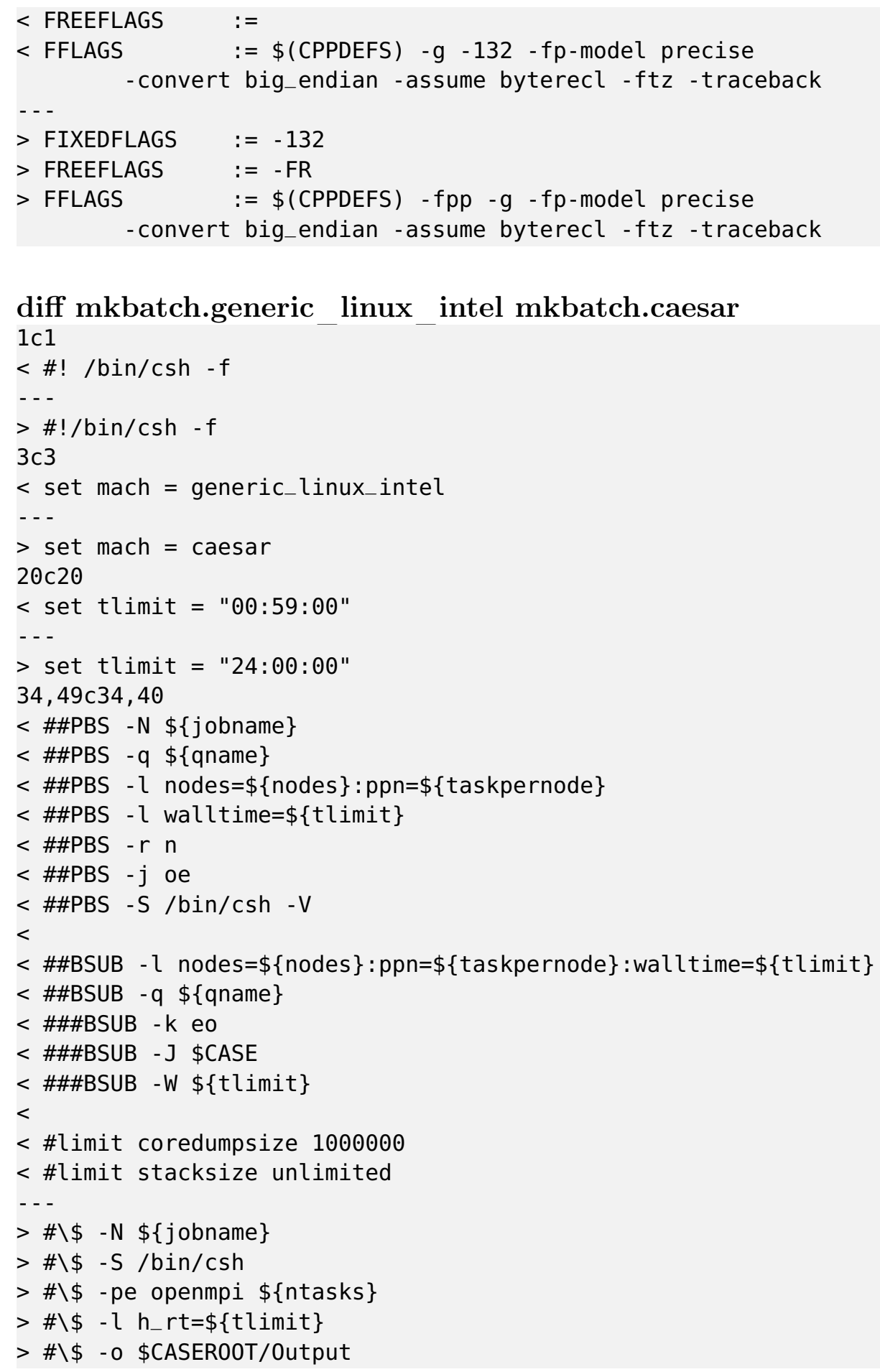




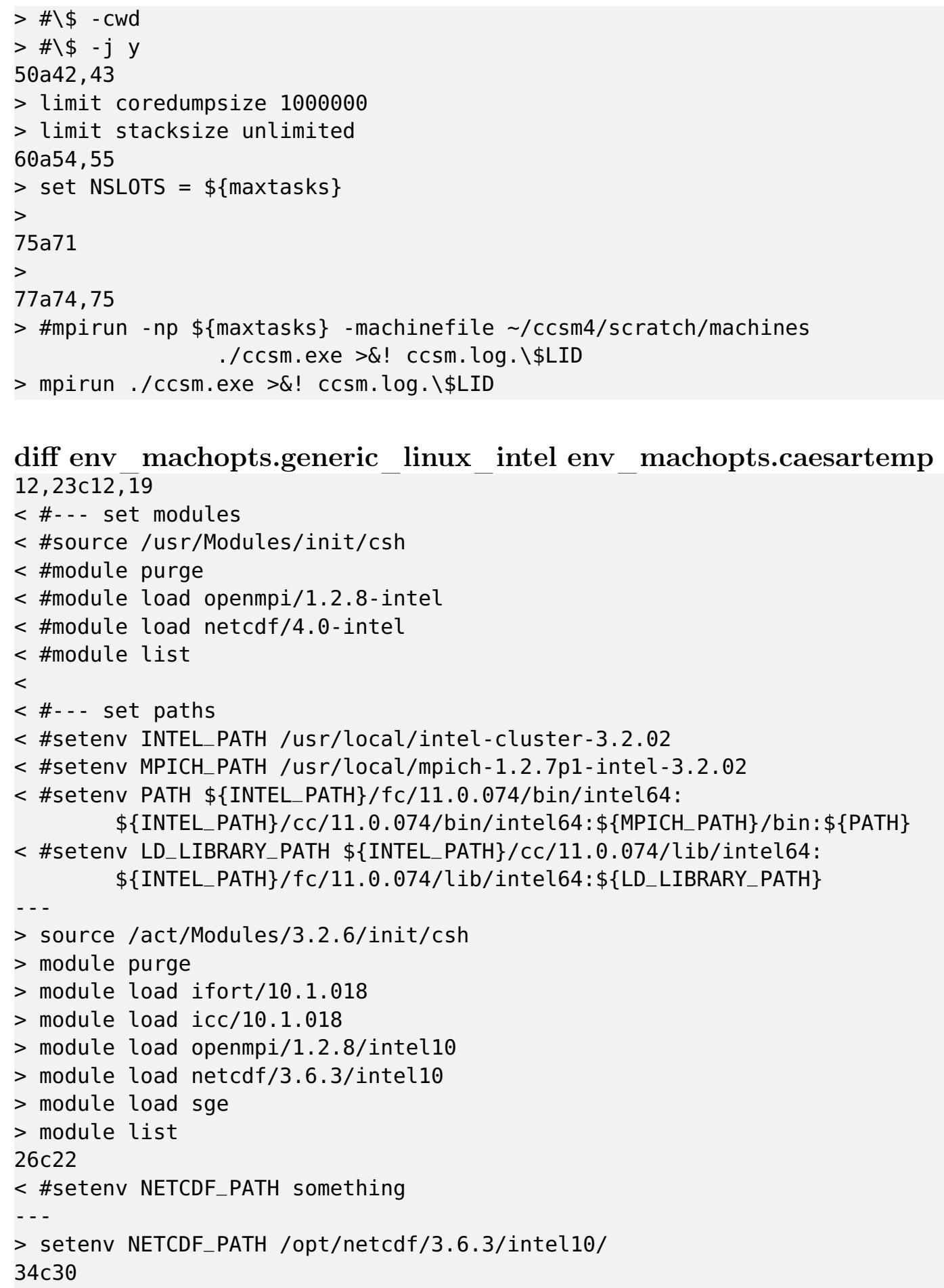


< \#setenv P4_GLOBMEMSIZE 500000000

- - -

> setenv P4_GLOBMEMSIZE 500000000

Once added, these three custom machine configuration files allow the user to create CESM cases using the 'create_newcase' command and the 'caesar' machine name. For example, a dry run (using inactive model components) can be created for testing purposes in the 'scripts' folder by entering the following command:

\section{Creating CESM Dry Run}

./create_newcase -case TEST_X I -mach caesar 1

- compset X 1

-res f19_g16

After entering the TEST_X directory, the run can be started by configuring, building, and finally submitting the script:

\section{Submitting CESM Dry Run}

./configure - case

./TEST_X.caesar.build

./TEST_X.caesar.submit

In practice there are other steps involved for configuring run options, but these same three commands will always be performed at some point along the way.

To set load assignments for each model component in CESM, the xmlchange utility (included in CESM) can be invoked in a newly created case directory with the desired values of NTASKS (number of cores assigned) and ROOTPE (starting core number) for each model. For example, to instruct each model to run sequentially, using 96 cores each, the following commands could be executed.

\section{Sequential Core Assignment Commands}

./xmlchange -file env_mach_pes.xml -id NTASKS_ATM - val 96

./xmlchange -file env_mach_pes.xml -id RO0TPE_ATM - val 0

./xmlchange -file env_mach_pes.xml -id NTASKS_LND -val 96 


\begin{abstract}
./xmlchange -file env_mach_pes.xml -id R00TPE_LND -val 0 ./xmlchange -file env_mach_pes.xml -id NTASKS_ICE - val 96 ./xmlchange -file env_mach_pes.xml -id ROOTPE_ICE - val 0 ./xmlchange -file env_mach_pes.xml -id NTASKS_OCN - val 96 ./xmlchange -file env_mach_pes.xml -id ROOTPE_OCN - val 0 ./xmlchange -file env_mach_pes.xml -id NTASKS_CPL - val 96 ./xmlchange -file env_mach_pes.xml -id R00TPE_CPL -val 0 ./xmlchange -file env_mach_pes.xml -id NTASKS_GLC - val 96 ./xmlchange -file env_mach_pes.xml -id R00TPE_GLC -val 0
\end{abstract}

